\title{
Treatment of Yellow Phosphorus Slag and Reuse of It as an Absorbent of Chromium (VI) Ions and Methylene Blue
}

\author{
Van Hai Nguyen, ${ }^{1}$ Van Chien Nguyen, ${ }^{2}$ Thuy Chinh Nguyen $\mathbb{D D}^{2,3}$ Do Mai Trang Tran, ${ }^{2}$ \\ Thi Thu Trang Nguyen, ${ }^{1}$ Quoc Trung Vu, ${ }^{1}$ Duy Trinh Nguyen, ${ }^{4}$ and Hoang Thai $\mathbb{D}^{2,3}$ \\ ${ }^{1}$ Faculty of Chemistry, Hanoi National University of Education, 136 Xuan Thuy Road, Cau Giay, Ha Noi 100000, Vietnam \\ ${ }^{2}$ Institute for Tropical Technology, Vietnam Academy of Science and Technology, 18, Hoang Quoc Viet, Cau Giay, \\ Ha Noi 100000, Vietnam \\ ${ }^{3}$ Graduate University of Science and Technology, Vietnam Academy of Science and Technology, 18 Hoang Quoc Viet, Cau Giay, \\ Ha Noi 100000, Vietnam \\ ${ }^{4}$ Nguyen Tat Thanh University, 300A Nguyen Tat Thanh, District 4, Ho Chi Minh City 700000, Vietnam
}

Correspondence should be addressed to Thuy Chinh Nguyen; thuychinhhn@gmail.com and Hoang Thai; hoangth@itt.vast.vn

Received 4 February 2020; Revised 8 May 2020; Accepted 3 June 2020; Published 26 June 2020

Academic Editor: João Paulo Leal

Copyright ( 2020 Van Hai Nguyen et al. This is an open access article distributed under the Creative Commons Attribution License, which permits unrestricted use, distribution, and reproduction in any medium, provided the original work is properly cited.

\begin{abstract}
Yellow phosphorus is used widely in the world for production of phosphoric acid, various phosphates, flame retardant, detergent, water treatment, metal surface treatment, etc. After the production of yellow phosphorus, a large amount of phosphorus sludge is discharged to environment, causing environment pollution. This work focused on treatment of yellow phosphorus slag (YPS) and application of it as an absorbent for chromium (VI) ion and methylene blue. The YPS was first washed with water to remove phosphoferrite $(\mathrm{FeP})$ and impurities and then being milled and transferred to a float sorting system to obtain YPS particles. The characteristics of YPS particles were determined by inductively coupled plasma-mass-spectrometry (ICP-MS), energy-dispersive X-ray spectroscopy (EDX), infrared spectroscopy (IR), scanning electron microscopy (SEM), X-ray diffraction (XRD), zeta potential, and nitrogen adsorption methods. The YPS particles were retreated with $\mathrm{NaOH}, \mathrm{HNO}_{3}$, and EDTA solutions to evaluate the influence of these agents on metal ion and organic compound adsorption ability by YPS. The adsorption parameters of chromium (VI) ion and methylene blue (MB) by treated YPS particles were recognized by the ultraviolet-visible (UV-Vis) spectrometer. The effects of temperature, $\mathrm{pH}$ solution, and initial concentration of absorbed substances on the adsorption ability were investigated. The adsorption isotherms and adsorption kinetics of chromium (VI) ion and MB by YPS particles were also determined. The obtained results confirmed that the green technology used to treat the YPS2 particles is suitable to obtain an effective absorbent. The adsorption efficiency of YPS2 particles for removal of chromium (VI) ions is smaller than that for removal of $\mathrm{MB}$ in aqueous solutions. The adsorption isotherm of MB adsorption process is complied with the Langmuir isotherm while the adsorption kinetic fits well with the pseudo-second-order reaction model. The thermodynamic parameters of MB adsorption processed on YPS2 were calculated and discussed.
\end{abstract}

\section{Introduction}

Yellow phosphorus slag (YPS) is a waste product of manufacturing yellow phosphorus $\left(\mathrm{P}_{4}\right)$ using the electrical furnace method at $1400^{\circ} \mathrm{C}-1600^{\circ} \mathrm{C}$ [1]. The worldwide yellow phosphorus production yields an average of 1.5 million tons of $\mathrm{P}_{4}$ each year [2]. In which, the countries discharge a large YPS weight including Chinese (75\%), Kazakhstan (13\%),
America (8\%), Western Europe (6\%), Russia (4\%), and the rest of India. For each ton of manufactured $\mathrm{P}_{4}$, about 8 to 10 tons of yellow phosphorus slag are produced [1]. This waste product is often left accumulated in the landfills, proposing a potential pollution thread to the environment. The majority of YPS particles compose of $\mathrm{CaO}$ and $\mathrm{SiO}_{2}$, accounting for approximately $85 \%$ of the slag mass [3]. Other components of the YPS are $\mathrm{Al}_{2} \mathrm{O}_{3}, \mathrm{Fe}_{2} \mathrm{O}_{3}, \mathrm{MgO}$, and some rare earth 
metals $[4,5]$. In Vietnam, the $\mathrm{P}_{4}$ is mainly produced and supplied by Lao Cai Yellow Phosphorus JSC (Tang Loong Industrial Zone, Bao Thang District, Lao Cai Province, Vietnam), with the productivity of 93,800 tons $\mathrm{P}_{4} /$ year and about 750,000-1,031,000 tons of YPS waste are produced and released directly into the surrounding environment [6]. Therefore, it is important to find different ways to utilize this waste product. Recent studies have been focusing on applying YPS into asphalt or asphalt binder $[7,8]$, cemented backfilling [9], retarding the early hydration of cement [10] or recovering rare earth metals [5].

YPS had been treated by different technologies and methods [11-13]. In German Auslegeschrift No. 1,804,172, the YPS particles were heat treated at $1000^{\circ} \mathrm{C}$ to $1100^{\circ} \mathrm{C}$ in a rotary furnace [11]. In German Offenlegungsschrift No. $2,211,505$, a physical separation method, for example, by gravity separation with tetrabromoethane as the liquid phase, the refinement of silicate slag phase was reported [12]. US patent No. 4,243,425 presented a method for refining of silicatic slag phase with steam at a temperature between $600^{\circ} \mathrm{C}$ and softening temperature of the slag [13].

In this work, an effective method for treatment of YPS was developed. This is a combination of the water washing flotation system with milling and sorting flotation. The waste water system was treated to recover $\mathrm{P}_{2} \mathrm{O}_{5}, \mathrm{~F}$, and minerals for other applications. The advantages of this technology were low energy consumption, reduction of noise and dust pollution, closed technology, and environmental friendly and waste water can be easily processed and reused (about $80-90 \%$ ). The minimized weight of chemicals was used, and treatment process was carried in room temperature. This approached to the green technology, the general trend of the world.

The study on metal ion adsorption ability of YPS in aqueous solutions has been limited in the research. Herein, the YPS was chosen as an absorbent due to its silicate structure with high content of silica. Moreover, the small size particle as compared with micrometer inorganic additives is an advantage of the YPS. Hence, the obtained YPS could be expected to use as an absorbent for removing toxicity substances in aqueous solutions. In this paper, chromium (VI) and methylene blue have been chosen as the model substances to study the adsorption ability of YPS. Chromium, commonly found in various sources of industrial waste water, is one of the most toxic metal ions, which influences seriously the biodiversity of the environment and causes several health issues to humans. Chromium often comes from discharge of industrial activities such as leather tanning, electroplating, or textiles [14]. It exists in water with various oxidation forms, but mainly in trivalent and hexavalent state [15], in which the hexavalent state is considered the most toxic because it is easily dilution and can bioaccumulate in human organs [16]. Some studies reveal that $\mathrm{Cr}$ (VI) ions can cause digestive system and lungs cancer, gastrointestinal and dermatological problems, severe diarrhea, and hemorrhage [17-19]. Many materials have been utilized to adsorb $\mathrm{Cr}$ (VI) ions in aqueous solutions including banana peel [20], coffee resins [21], fly ash [22], groundnut hull [23], or zeolite $\mathrm{NaX}$ [24] and showed good results.
Dye has been an important ingredient in many common daily industries such as textile, leather, cosmetics, plastics, and food production [25]. Nevertheless, colored dye waste water constitutes considerable issues to the environment and water sources [26]. Complex aromatic molecular structures of dyes make them nondegradable [27]. Dyes, which have high demand for chemical and biological oxygen, high toxicity, and capability to hinder sunlight penetration into water bodies, are harmful pollutants to the aquatic ecosystem [28]. Methylene blue (MB), a cationic dye, is widely used in biology, medical science, chemistry, and dye field. However, long-term exposure to $\mathrm{MB}$ can cause certain symptoms and illnesses such as increased heart rate, vomiting, nausea, anemia, cyanosis, and tissue necrosis $[29,30]$. Various adsorbents have been used to adsorb MB in aqueous solutions with promising output such as activated carbon [29], natural clay [31], sea grass dead leaves [32], or modified pumice stone [33].

According to our calculation, the price of one tone of YPS at the Tang Loong Industrial Zone is only about 22 USD. This indicates that YPS product is cost-effective and promising for application not only as an absorbent but also as an additive for other fields (composites, paint, coating, etc.). Acids and bases are used for treatment of inorganic waste, for example, fly ash and gypsum, to improve the adsorption ability of these waste products [18, 20, 22, 23]. Besides, EDTA is known as a chemical used for both industrial and medical purposes. In the industry, it is mainly used to sequester metal ions in aqueous solution. Thanks to its high affinity for metal ions, EDTA can enormously enhance the chelation properties of the adsorbent. Therefore, in this work, $\mathrm{NaOH}, \mathrm{HNO}_{3}$, and EDTA were chosen for retreatment of YPS particles to evaluate their adsorption ability. We mainly focused on the characterization of YPS products as well as investigation of the factors affecting on the adsorption ability of YPS products for removal of chromium (VI) ions and methylene blue in aqueous solutions.

\section{Experiment}

2.1. Materials. Yellow phosphorus slag (YPS0) is waste product of Lao Cai Yellow Phosphorus JSC (Tang Loong Industrial Zone, Bao Thang District, Lao Cai Province, Vietnam) with a particle size of $50-100 \mu \mathrm{m}$; density of $2.75 \mathrm{~g} /$ $\mathrm{cm}^{3}$; hardness of 1-3; compressive strength of $80-100 \mathrm{MPa}$; water absorption of $1-4 \%$; and porosity of $10-12 \%$. Ethylenediaminetetraacetic acid (EDTA); 1,5-diphenylcarbazide (DCP); potassium chromate; and methylene blue (MB) were purchased from Merck Co. $\mathrm{HNO}_{3}$ and $\mathrm{NaOH}$ are the commercial products which are used as received.

\subsection{Surface Treatment of Yellow Phosphorus Slag}

\subsubsection{Treatment of Yellow Phosphorus Slag by Flotation} System. Firstly, the washing flotation system was used to remove preliminary soluble impurities and to separate the particles for next stage. In this stage, the large content of FeP, $\mathrm{P}_{2} \mathrm{O}_{5}$, fluorine compounds, and some other impurities were 
removed and the YPS0 was then wet sieved down to prepare a granular material which is smaller than $100 \mu \mathrm{m}$ in diameter (YPS1) (by sieve analysis). These particles could be applied for cement production or concrete directly. In the next stage, the particles were milled and transferred to a float sorting system to obtain particles in smaller size. The solid part was then rotated in a spinning double-drum composter and dried at $100^{\circ} \mathrm{C}$ until unchanged weight. The product was designed as YPS2 with the calcium silicate content in particles higher than $90 \%$. The waste water system was treated to recover $\mathrm{P}_{2} \mathrm{O}_{5}$, fluorine compounds, and minerals for other applications. The BET surface area/t-plot micropore area, pore diameter, and pore volume of YPS2 product are $1.3145 \mathrm{~m}^{2} \mathrm{~g}^{-1} / 0.3024 \mathrm{~m}^{2} \mathrm{~g}^{-1}, \quad 21.4897 \mathrm{~nm}, \quad$ and $0.000134 \mathrm{~cm}^{3} \mathrm{~g}^{-1}$, respectively (determined by the nitrogen adsorption method on a TriStar 3000 V6.07 A device).

2.2.2. Surface Treatment of Yellow Phosphorus Slag (YPS) Using $\mathrm{NaOH}$ and $\mathrm{HNO}_{3}$ Solutions. The YPS particles were retreated by $\mathrm{NaOH}$ or $\mathrm{HNO}_{3}$ solution as follows: $200 \mathrm{~mL}$ of $\mathrm{NaOH} 1 \mathrm{M}$ (or $\mathrm{HNO}_{3} 1 \mathrm{M}$ ) solution was added into a flask containing $20 \mathrm{~g}$ of YPS particles and stirred at $70^{\circ} \mathrm{C}$ for 3 hours. Then, the treated YPS particles by $\mathrm{NaOH}$ (or $\mathrm{HNO}_{3}$ ) solution were filtered and washed with distilled water until filtered aqueous solution reached to neutral medium ( $\mathrm{pH} 7$ ). After that, the treated YPS particles were dried in an oven at $100^{\circ} \mathrm{C}$ for 12 hours. The YPS0 particles and YPS2 particles which were treated with $\mathrm{NaOH}$ or $\mathrm{HNO}_{3}$ solution were designed as YPSO-NaOH, YPS2-NaOH, YPSO- $\mathrm{HNO}_{3}$, and YPS2- $\mathrm{HNO}_{3}$.

2.2.3. Surface Treatment of Yellow Phosphorus Slag (YPS) Using EDTA. In this research, YPS was modified by using EDTA as follows: $5 \mathrm{~g}$ of YPS was added into $100 \mathrm{~mL}$ distilled water in a $250 \mathrm{~mL}$ glass beaker containing $0.5 \mathrm{~g}$ of EDTA. This solution was then stirred on a magnetic machine at a speed of $500 \mathrm{rpm}$ for 2 hours at $60^{\circ} \mathrm{C}$. Next, the solution was filtered to obtain the solid part. Finally, the solid part was dried in an oven at $100^{\circ} \mathrm{C}$ for 3 hours.

\subsection{Characterizations}

2.3.1. Infrared Spectroscopy (IR). IR spectra of YPS samples were recorded using a Nicolet iS10 spectrometer (Thermo Scientific, USA) in the range of wavenumbers from $4000 \mathrm{~cm}^{-1}$ to $400 \mathrm{~cm}^{-1}$, resolution of $8 \mathrm{~cm}^{-1}$, and scan average of 32 times.

2.3.2. Energy-Dispersive X-Ray Spectroscopy (EDX). EDX spectra of the YPS samples were carried out on a SEM/EDS device (Oxford Instruments, UK).

2.3.3. Inductively Coupled Plasma-Mass-Spectrometry (ICP$M S)$. The element content of YPS samples was detected by NexION 2000 ICP-DRC-QMS (Perkin Elmer, USA).
2.3.4. Scanning Electron Microscopy (SEM). Scanning electron microscopy (SEM) of YPS samples was taken on a SEMS-4800 device (Hitachi, Japan). The samples were coated a Pt layer on the surface to enhance the resolution of images.

2.3.5. X-Ray Diffraction Analysis (XRD). XRD patterns of YPS samples were performed on a Siemens D5000 X-ray diffractometer (XRD) with $\mathrm{CuK}_{\alpha}$ radiation source $(\lambda=0.154 \mathrm{~nm})$ at $40 \mathrm{kV}$ generator voltage with $0.03^{\circ}$ step and $30 \mathrm{~mA}$ current by $0.043^{\circ}$ s scan speed in the range of $2 \theta$ from $2^{\circ}$ to $70^{\circ}$.

2.3.6. Zeta Potential. Zeta potential of the YPS2 sample was conducted on a Zetasizer, ver. 6.2, Malvern Instruments, with zeta runs of 12 , count rate (kcps) of 288.7, and measurement position of $4.5 \mathrm{~mm}$ at $25^{\circ} \mathrm{C}$. The YPS2 was dispersed in water $(\mathrm{pH} \approx 7)$ with its dispersant RI of 1.330 , viscosity of $0.8872 \mathrm{cP}$, and dispersant dielectric constant of 78.5 .

2.3.7. Ultraviolet-Visible (UV-Vis) Absorption Spectrometry. Spectra of samples were determined on a UV spectrophotometer (CINTRA 40, GBC, USA) in the range of wavelength from 200 to $800 \mathrm{~nm}$.

2.4. Determination of Adsorption Ability of Yellow Phosphorus Slag in Aqueous Solution. An exact weight of the YPS samples was added into a $100 \mathrm{~mL}$ of $\mathrm{Cr}$ (VI) or MB solution. The solution was stirred on a magnetic stirrer at room temperature for 120 minutes. The solution was then filtered, and $25 \mathrm{~mL}$ of aliquots was withdrawn. For MB adsorption, the withdrawn solution was monitored by a UV-Vis spectrophotometer (CINTRA 40, GBC, USA) at $\lambda_{\max }=664 \mathrm{~nm}$. For $\mathrm{Cr}$ (VI) adsorption, $1 \mathrm{~mL}$ of $\mathrm{H}_{2} \mathrm{SO}_{4} 1 \mathrm{M}$ and $1 \mathrm{~mL}$ of DCP $0.5 \%$ solution were introduced into the withdrawn solution and this solution was kept for 10 minutes before taking on a $\mathrm{UV}-\mathrm{V}$ is spectrophotometer at $\lambda_{\max }=540 \mathrm{~nm}$. All studies were performed in triplicate to increase accuracy.

\subsection{Determination of Cr (VI) Ion and Methylene Blue Adsorption Isotherms and Adsorption Kinetics of Yellow Phosphorus Slag}

2.5.1. Adsorption of $\mathrm{Cr}$ (VI) Ions and Methylene Blue Using YPS Samples. The amount of adsorbate per amount of adsorbent at equilibrium condition, $Q(\mathrm{mg} / \mathrm{g})$, was calculated as follows:

$$
Q=\frac{\left(C_{\mathrm{o}}-C_{\mathrm{e}}\right) \cdot V}{W}
$$

where $C_{\mathrm{o}}$ and $C_{\mathrm{e}}$ are the concentration of adsorbate in solution at initial and equilibrium $(\mathrm{mg} / \mathrm{L}), V$ is the solution volume $(\mathrm{L})$, and $W$ is the mass of YPS samples $(\mathrm{g})$.

The percentage of metal ions removed, $H(\%)$, was calculated using the following equation: 


$$
H=\frac{\left(C_{\mathrm{o}}-C_{\mathrm{e}}\right) \cdot 100}{C_{\mathrm{e}}}
$$

2.5.2. Adsorption Isotherms. In this work, we study the adsorption behavior in the solid-liquid system using four adsorption isotherms: Langmuir, Freundlich, Temkin, and Dubinin-Radushkevich isotherms.

Langmuir isotherm equation for ion adsorption:

$$
Q_{\mathrm{e}}=\frac{Q_{\mathrm{o}} K_{\mathrm{L}} C_{\mathrm{e}}}{1+K_{\mathrm{L}} C_{\mathrm{e}}}
$$

where $Q_{0}$ is the maximum monolayer adsorption capacity $(\mathrm{mg} / \mathrm{g})$ and $k_{\mathrm{L}}$ is the Langmuir isotherm constant representing binding energy of the adsorption system ( $\mathrm{L} / \mathrm{mg})$.

Freundlich isotherm equation:

$$
\mathrm{Q}_{\mathrm{e}}=k_{\mathrm{F}} C_{\mathrm{e}}^{\left(1 / n_{\mathrm{F}}\right)},
$$

where $k_{\mathrm{F}}$ is the Freundlich isotherm constant $(\mathrm{mg} / \mathrm{g})$ indicating adsorption capacity and $n_{\mathrm{F}}$ is adsorption intensity.

Temkin isotherm equation:

$$
Q_{\mathrm{e}}=B \ln A_{\mathrm{T}}+B \ln C_{\mathrm{e}}, \quad \text { with } B=\frac{\mathrm{RT}}{b_{\mathrm{T}}},
$$

where $A_{\mathrm{T}}$ is the Temkin isotherm equilibrium binding constant $(\mathrm{L} / \mathrm{g}), b_{\mathrm{T}}$ is the Temkin isotherm constant related to heat sorption $(\mathrm{J} / \mathrm{mg}), T$ is absolute temperature $(\mathrm{K})$, and $R$ is the gas constant $(8.314 \mathrm{~J} / \mathrm{mol} / \mathrm{K})$.

Dubinin-Radushkevich (DR) isotherm equation:

$\ln Q_{\mathrm{e}}=\ln Q_{\mathrm{s}}-K_{\mathrm{ad}} \varepsilon^{2}, \quad$ with $\varepsilon=\mathrm{RT} \ln \left(1+\frac{1}{C_{\mathrm{e}}}\right)$,

where $Q_{\mathrm{s}}$ is the theoretical isotherm saturation capacity (mg/g) and $K_{\mathrm{ad}}$ is the Dubinin-Radushkevich isotherm constant $\left(\mathrm{mol}^{2} / \mathrm{kJ}^{2}\right)$.

2.5.3. Adsorption Kinetics. Adsorption kinetics were studied using four reaction models: first-order, pseudo-first-order, second-order, and pseudo-second-order reaction models.

First-order reaction model:

$$
\ln C_{\mathrm{t}}=\ln C_{\mathrm{o}}-k_{1} t .
$$

Pseudo-first-order reaction model:

$$
\ln \left(Q_{\mathrm{o}}-Q_{\mathrm{t}}\right)=\ln Q_{\mathrm{o}}-k_{\mathrm{s} 1} t .
$$

Second-order reaction model:

$$
\frac{1}{C_{\mathrm{t}}}=\frac{1}{C_{\mathrm{o}}}+k_{2} t \text {. }
$$

Pseudo-second-order reaction model:

$$
\begin{aligned}
\frac{1}{\left(Q_{\mathrm{e}}-Q_{\mathrm{t}}\right)} & =\frac{1}{Q_{\mathrm{e}}}+k_{\mathrm{s} 2} t \longrightarrow \frac{t}{Q_{\mathrm{t}}} \\
& =\frac{1}{h}+\frac{1}{Q_{\mathrm{e}}} t, \quad \text { with } h=k_{\mathrm{s} 2} \mathrm{Qe}^{2},
\end{aligned}
$$

where $Q_{0}$ is the maximum monolayer coverage capacity (mg/g); $Q_{\mathrm{e}}$ and $Q_{\mathrm{t}}$ are the amount of adsorbate adsorbed per gram of adsorbent at equilibrium time and testing time $t(\mathrm{mg} / \mathrm{g}) ; C_{\mathrm{o}}$ and $C_{\mathrm{t}}$ are the solution concentration at the initial time and the testing time $t$ (mg/l); and $k_{1}, k_{\mathrm{s} 1}, k_{2}$, and $k_{\mathrm{s} 2}$ are the rate constant (per minute) of the first-order reaction model, pseudo-firstorder reaction model, second-order reaction model, and pseudo-second-order reaction model, respectively.

\section{Results and Discussion}

\subsection{Characteristics of Yellow Phosphorus Slag (YPS) Samples}

3.1.1. FTIR Spectra of YPS Samples. Figure 1 shows FTIR spectra of the YPS samples. It can be seen that the absorption peaks of YPS samples mostly appeared in the wavenumber range of $1500-500 \mathrm{~cm}^{-1}$. In the low frequency region, the deformation vibration of bridge $\mathrm{Si}-\mathrm{O}-\mathrm{Si}$ and terminal $\mathrm{O}-\mathrm{Si}-\mathrm{O}$ groups and the metal-oxygen polyhedral $\left(\mathrm{CaO}_{\mathrm{n}}\right)$ results in the absorption bands of about $550 \mathrm{~cm}^{-1}$. The adsorption peak at $699 \mathrm{~cm}^{-1}$ assigned to the $\mathrm{Al}-\mathrm{O}$ and $\mathrm{Si}-\mathrm{O}$ bonds and showed the presence of pseudowollastonite $\alpha-\mathrm{CaSiO}_{3}$ in the slag. The spectra from $750 \mathrm{~cm}^{-1}$ to $1050 \mathrm{~cm}^{-1}$ with the peak at 872 and $920 \mathrm{~cm}^{-1}$ correspond to the stretching vibration of $\mathrm{Si}-\mathrm{O}$ groups, indicating the presence of the glass-like earth silicon. Numerous unbridged connections of $\mathrm{Si}-\mathrm{O}$ emerging are the result of breach of the polymer network $\mathrm{Si}-\mathrm{O}-\mathrm{Si}$ of the frame due to the introduction of $\mathrm{Ca}$ atoms for replacement of $\mathrm{Si}$ atoms in the $\mathrm{Si}-\mathrm{O}-\mathrm{Si}$ network. Furthermore, the peaks at 1414 and $1484 \mathrm{~cm}^{-1}$ represent the vibration of $\mathrm{CO}_{3}^{2-}$ in calcite, one of main compositions of YPS samples. This result is similar to the report of Zinesh et al. [34].

3.1.2. Energy-Dispersive X-Ray Spectroscopy (EDX). Figure 2 presents SEM/EDX images of the YPS samples. By observing the SEM images of the samples, it can be seen that after treatment by water and milling, the size of YPS particles was reduced significantly. So, this technology is suitable for obtaining the YPS particles with finer size. From the EDX spectra and data in Table 1, the YPS samples are mainly composed of $\mathrm{O}, \mathrm{Ca}$, and $\mathrm{Si}$ (total content of $\mathrm{O}+\mathrm{Ca}+\mathrm{Si}$ over 90\%). Other elements such as $\mathrm{Mg}, \mathrm{K}, \mathrm{S}, \mathrm{P}$, and F were also appeared in all YPS samples with the percentage of each element less than 2\%. Additionally, rare earth elements that are highly chemical active such as $\mathrm{Pm}, \mathrm{Sm}, \mathrm{Ce}, \mathrm{Pr}$, and $\mathrm{Nd}$ occupy a relatively high content in the sample. Furthermore, the pretreatment process does not affect much on the content of most of the elements. 


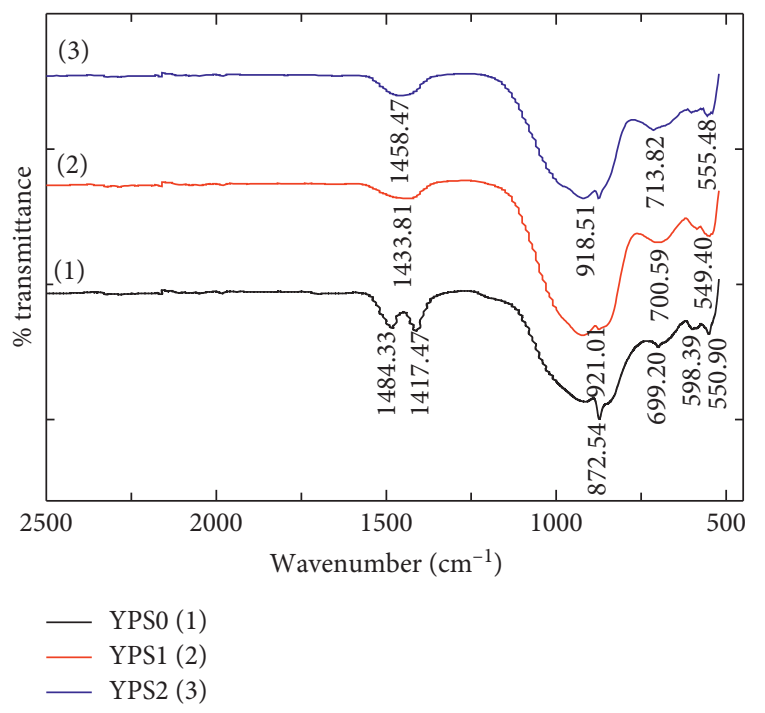

FIGURE 1: FTIR spectra of YPS samples.

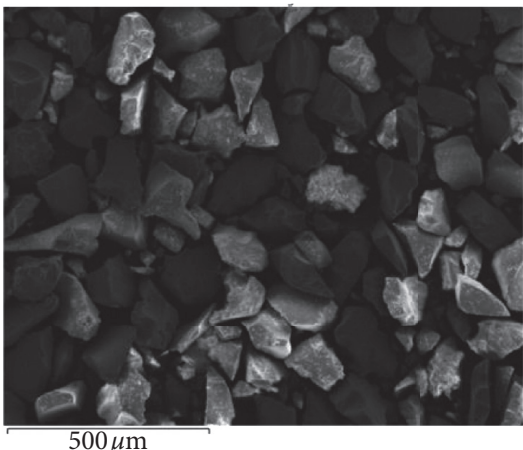

(a)

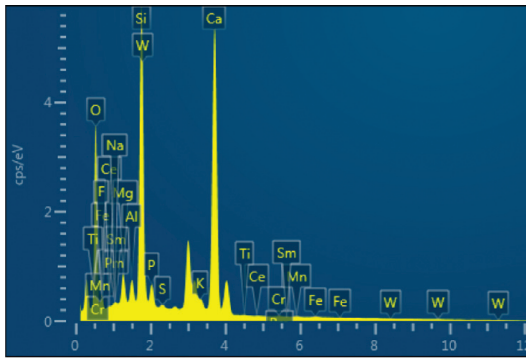

(d)

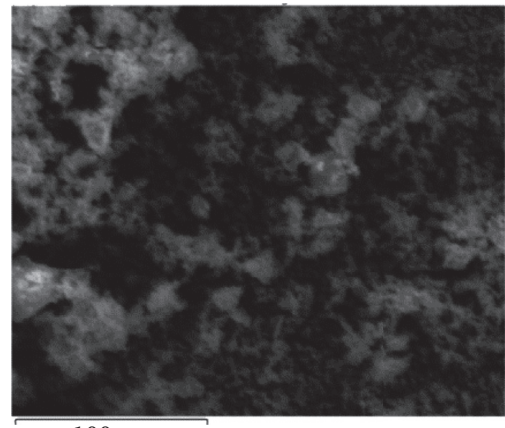

$100 \mu \mathrm{m}$

(b)

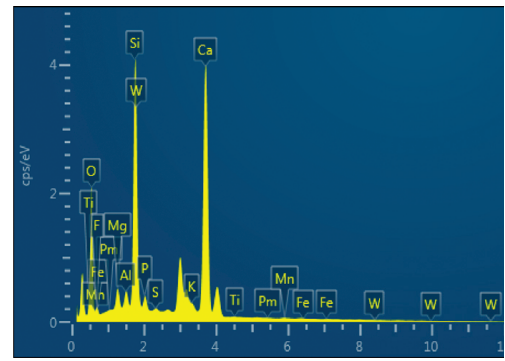

(e)

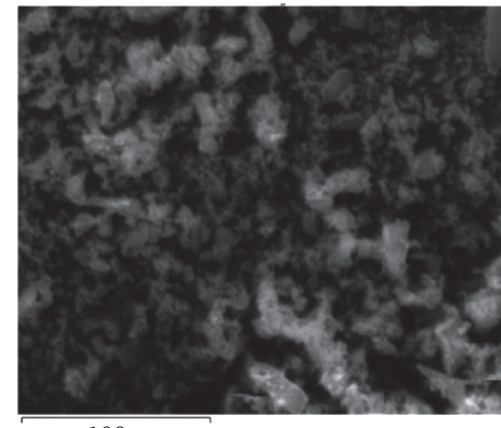

$100 \mu \mathrm{m}$

(c)

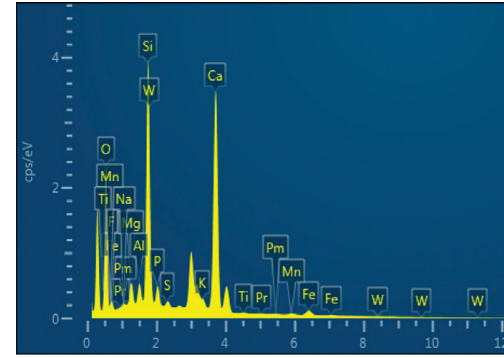

(f)

FIgURE 2: SEM images and EDX spectra of YPS samples. YPS0 (a, d); YPS1 (b, e); YPS2 (c, f).

3.1.3. X-Ray Diffraction (XRD). The crystallographic structure of YPS samples before and after treatment was determined by using the X-ray diffraction method. The results of XRD analysis of YPS particles are performed in Figures 3-5. Figure 3 shows the XRD pattern of the raw YPS sample. In the XRD pattern of the YPS0 sample, the appearance of calcium phosphate $\beta$ crystal and hatrurite crystal (ref. PDF 00-009-0346 and 01-073-0599) was observed. The peak intensity of calcium phosphate $\beta$ crystal in the XRD pattern of YPS0 is stronger than that of hatrurite crystal, indicating that calcium phosphate $\beta$ crystal makes up the most part in the crystallographic structure of the YPS0 sample. After treating according to the first stage to eliminate impurities, the YPS1 sample contains calcium phosphate $\beta$ crystals (ref. PDF 00009-0346) and the hatrurite crystal was removed. The YPS2 sample only contains calcium phosphate $\beta$ crystals. This result proved that the calcium phosphate was detached after treatment process. The diffraction peaks characterized for calcium phosphate $\beta$ crystals in the XRD pattern of YPS samples were placed at the diffraction angles, $2 \theta=20.53^{\circ}$, $31.78^{\circ}$, and $55.92^{\circ}$ corresponding to the crystal size of $4.32 \AA$, $2.81 \AA$, and $1.64 \AA$, respectively. 
TABLE 1: Average weight (\%) of elements in YPS samples.

\begin{tabular}{|c|c|c|c|c|}
\hline No. & Element & YPS0 & YPS1 & YPS2 \\
\hline 1 & $\mathrm{O}$ & 46.73 & 48.15 & 46.57 \\
\hline 2 & $\mathrm{Si}$ & 13.32 & 13.08 & 13.91 \\
\hline 3 & $\mathrm{Ca}$ & 29.25 & 26.40 & 29.95 \\
\hline 4 & $\mathrm{Mg}$ & 1.56 & 1.45 & 1.47 \\
\hline 5 & $\mathrm{~K}$ & 0.42 & 0.49 & 0.39 \\
\hline 6 & $\mathrm{Cr}$ & 0.11 & - & - \\
\hline 7 & $\mathrm{Mn}$ & 0.30 & 0.36 & 0.18 \\
\hline 8 & $\mathrm{Na}$ & 0.17 & 0.24 & - \\
\hline 9 & $S$ & 0.24 & 0.46 & 0.30 \\
\hline 10 & $\mathrm{P}$ & 1.29 & 1.48 & 1.11 \\
\hline 11 & $\mathrm{~F}$ & 3.88 & 3.32 & 3.67 \\
\hline 12 & $\mathrm{Al}$ & 1.03 & 1.10 & 0.99 \\
\hline 13 & W & 0.98 & 0.74 & 0.78 \\
\hline 14 & $\mathrm{Fe}$ & 0.49 & 2.24 & 0.21 \\
\hline 15 & $\mathrm{Ti}$ & 0.07 & 0.15 & 0.07 \\
\hline 16 & $\mathrm{Pm}$ & 0.07 & 0.26 & 0.17 \\
\hline 17 & $\mathrm{Sm}$ & 0.24 & - & 0.14 \\
\hline 18 & $\mathrm{Ce}$ & 0.10 & 0.14 & 0.12 \\
\hline 19 & $\operatorname{Pr}$ & 0.22 & 0.14 & 0.16 \\
\hline \multirow[t]{2}{*}{20} & $\mathrm{Nd}$ & 0.24 & - & 0.23 \\
\hline & Total & 100 & 100 & 100 \\
\hline
\end{tabular}

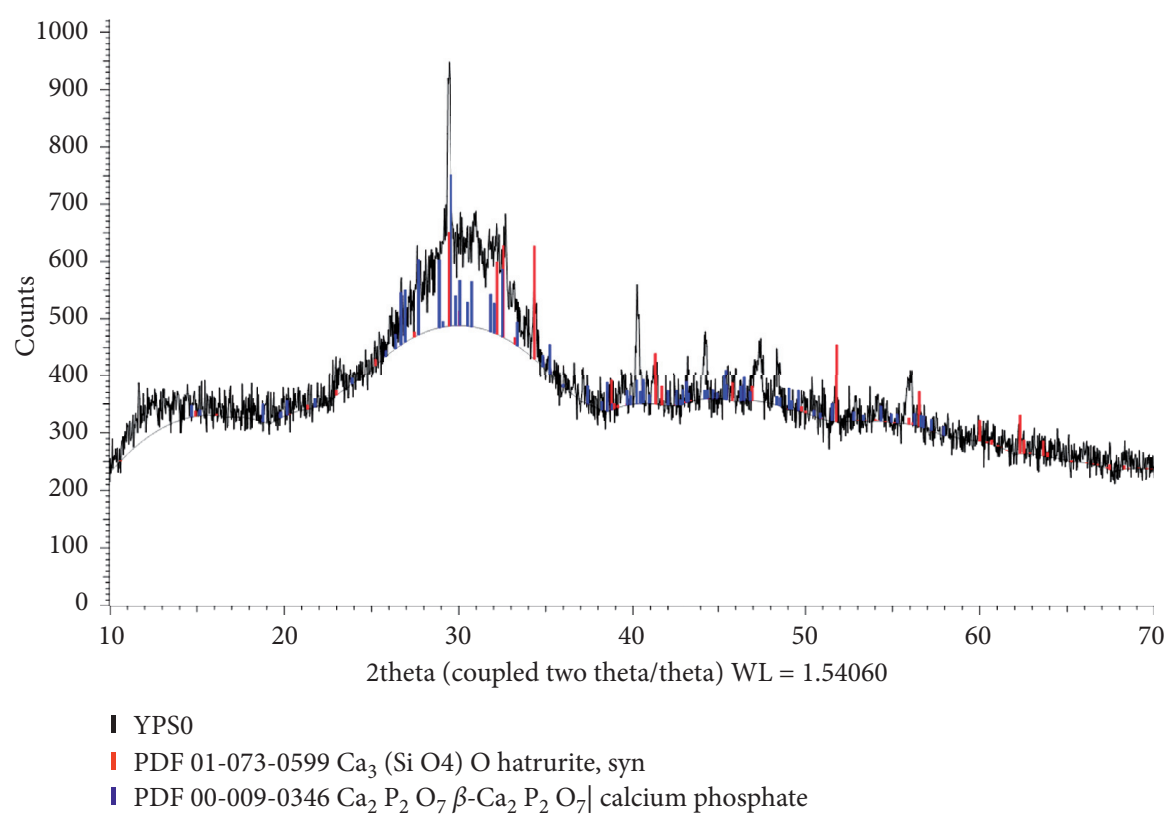

FIGURE 3: XRD pattern of the YPS0 sample.

3.1.4. ICP-MS Spectra. Table 2 demonstrates the chemical composition of the YPS1 and YPS2 samples after treatments. As can be seen from this table, $\mathrm{CaO}$ and $\mathrm{SiO}_{2}$ compose of approximately $80 \%$ of the pretreated YPS samples with each compound accounts for about $40 \%$ of the samples. It is noticeable that the percentage of $\mathrm{P}_{2} \mathrm{O}_{5}$ decreased greatly after the second treatment process, from $1.30 \%$ in the YPS1 sample to $0.01 \%$ in the YPS2 sample. Other metal elements such as $\mathrm{Al}, \mathrm{Fe}$, and $\mathrm{Mn}$ occupy a very small part in the sample, but they were still remained after treatment process. As mentioned above, the above YPS samples also contain rare earth metals and the treatment process did not affect much on their content in YPS samples. This is in agreement with the publication of Ming et al. [35].

3.1.5. Morphology of YPS Samples. Figure 6 expresses FESEM images of YPS0 and YPS2 samples at magnification of 5000 times and 50000 times. It is clear that the wet milling can reduce the size of the YPS particles, making them finer in size. After treatment, the common particle size of YPS2 particles is about $10 \mu \mathrm{m}$. Furthermore, many particles of size 100-400 $\mathrm{nm}$ can be observed on the surface of these particles (Figures 6(b) and 6(d)). 


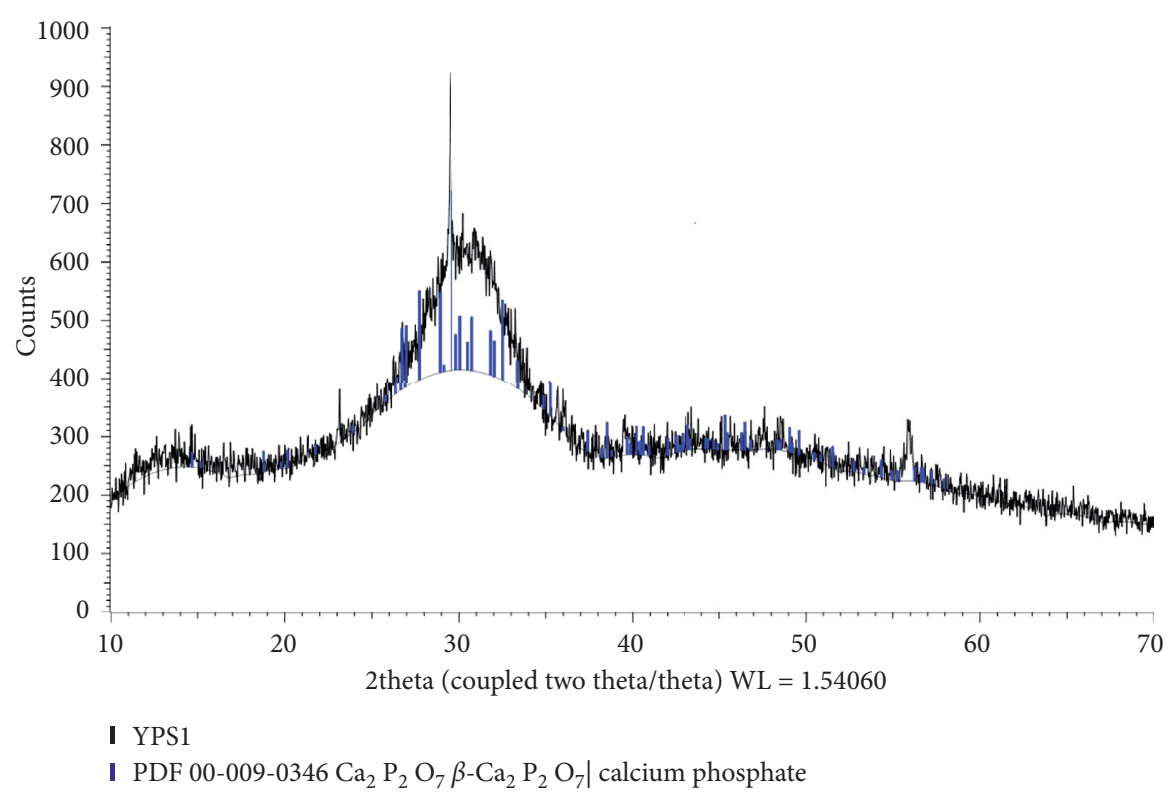

FIGURE 4: XRD pattern of the YPS1 sample.

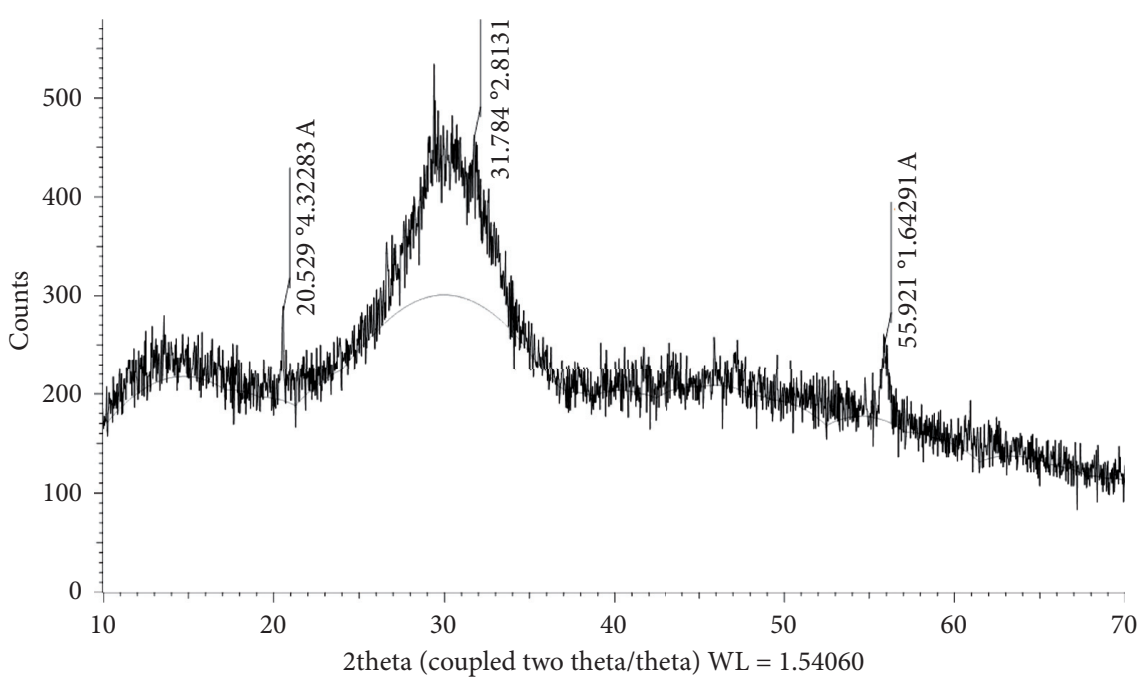

FIGURE 5: XRD pattern of the YPS2 sample.

From above results and comparing with other methods, it can be concluded that wet milling technology is effective for treatment of YPS to obtain the YPS particles with finer size and high purity at cheap cost. These YPS particles are potential for further advanced applications, for examples, additives for preparation of polymer composites, coating, paint, rubber, flame retardants, absorbents, etc. The similar finding can be seen in the report of Huang et al. [36].

3.1.6. Zeta Potential. Figure 7 shows the zeta potential distribution diagram of the YPS2 sample. It can be seen that YPS2 particles had a negative charge ranged in $-30 \mathrm{mV}-0 \mathrm{mV}$ with a mean value of $-15.3 \mathrm{mV}$. The negative charge on the surface of YPS2 can be due to the presence of $\mathrm{CaO}$ and calcite in composition of YPS2.

\subsection{Use of YPS Particles as Absorbents}

3.2.1. Chromium (VI) Ion Adsorption Ability of YPS Particles. Table 3 shows $\mathrm{Cr}(\mathrm{VI})$ ion removal efficiency $(H)$ and amount of Cr (VI) ions removed per gram of YPS samples before and after treatment by $\mathrm{NaOH}, \mathrm{HNO}_{3}$, and EDTA solutions $(Q)$. The adsorption condition is fixed as follows: the weight of adsorbent is 0.5 gram, concentration of $\mathrm{Cr}$ (VI) ions is $10 \mathrm{ppm}$, and adsorption time is 120 minutes. It is clear that the YPS0 and modified raw YPS samples treated by $\mathrm{NaOH}$ and $\mathrm{HNO}_{3}$ solutions displayed poor Cr (VI) ion adsorption ability with the removal efficiencies are all less than $11 \%$ (no. 1 , no. 4 , and no. 5 ), hence not suitable for adsorption process, and further treatment of the YPS samples is necessary. The raw YPS sample after water treatment (YPS1) presented much higher adsorption ability, 
TABLE 2: Composition of YPS samples obtained from the ICP method.

\begin{tabular}{|c|c|c|c|c|}
\hline No. & Target & Unit & YPS1 & YPS2 \\
\hline 1 & $\mathrm{CaO}$ & $\%$ & 38.84 & 41.15 \\
\hline 2 & $\mathrm{SiO}_{2}$ & $\%$ & 39.17 & 38.67 \\
\hline 3 & $\mathrm{P}_{2} \mathrm{O}_{5}$ & $\%$ & 1.30 & 0.01 \\
\hline 4 & $\mathrm{Fe}$ & $\mathrm{mg} / \mathrm{kg}$ & 1425.00 & 1142.59 \\
\hline 5 & $\mathrm{Al}$ & $\mathrm{mg} / \mathrm{kg}$ & 7000.00 & 6172.60 \\
\hline 6 & $\mathrm{Mn}$ & $\mathrm{mg} / \mathrm{kg}$ & 798.08 & 846.15 \\
\hline 7 & $\mathrm{Ti}$ & $\mathrm{mg} / \mathrm{kg}$ & 28461.54 & 26078.80 \\
\hline 8 & $\mathrm{Ni}$ & $\mathrm{mg} / \mathrm{kg}$ & 969.23 & 260.79 \\
\hline 9 & $\mathrm{Ba}$ & $\mathrm{mg} / \mathrm{kg}$ & 257.69 & 202.63 \\
\hline 10 & $\mathrm{Sr}$ & $\mathrm{mg} / \mathrm{kg}$ & 798.08 & 819.89 \\
\hline 11 & $\mathrm{Zn}$ & $\mathrm{mg} / \mathrm{kg}$ & 49.42 & 66.23 \\
\hline 12 & $\mathrm{Cr}$ & $\mathrm{mg} / \mathrm{kg}$ & 16.46 & 18.42 \\
\hline 13 & $\mathrm{Cu}$ & $\mathrm{mg} / \mathrm{kg}$ & 6.73 & 10.56 \\
\hline 14 & $\mathrm{Pt}$ & $\mathrm{mg} / \mathrm{kg}$ & 0.04 & 0.03 \\
\hline 15 & $\mathrm{Rb}$ & $\mathrm{mg} / \mathrm{kg}$ & 6.37 & 9.27 \\
\hline 16 & $\mathrm{Sb}$ & $\mathrm{mg} / \mathrm{kg}$ & 1.53 & 2.53 \\
\hline 17 & $\mathrm{Se}$ & $\mathrm{mg} / \mathrm{kg}$ & 0.43 & 0.93 \\
\hline 18 & Sn & $\mathrm{mg} / \mathrm{kg}$ & 0.65 & 1.58 \\
\hline 19 & $\mathrm{Tl}$ & $\mathrm{mg} / \mathrm{kg}$ & 0.02 & 0.02 \\
\hline 20 & $\mathrm{U}$ & $\mathrm{mg} / \mathrm{kg}$ & 3.73 & 4.37 \\
\hline 21 & $\mathrm{~V}$ & $\mathrm{mg} / \mathrm{kg}$ & 5.52 & 5.18 \\
\hline 22 & $\mathrm{~W}$ & $\mathrm{mg} / \mathrm{kg}$ & 0.86 & 0.41 \\
\hline
\end{tabular}

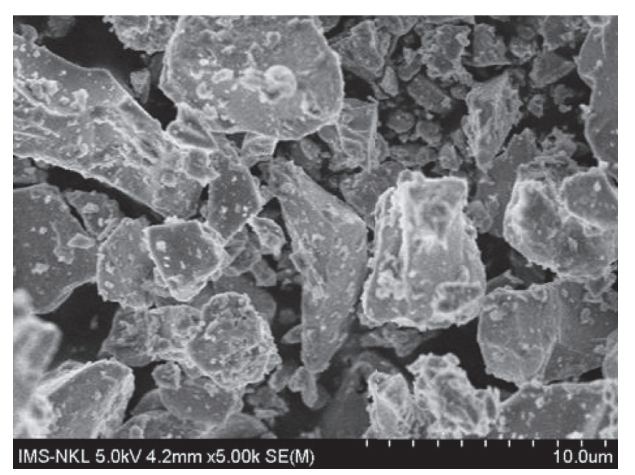

(a)

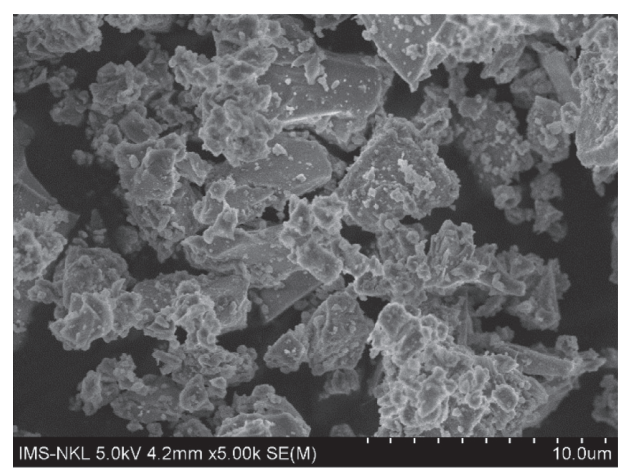

(c)

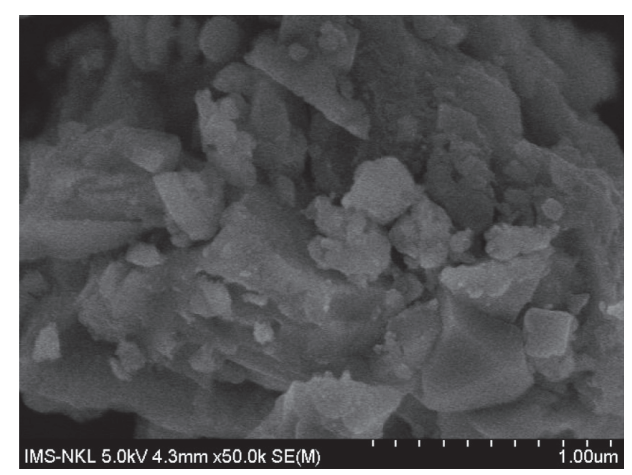

(b)

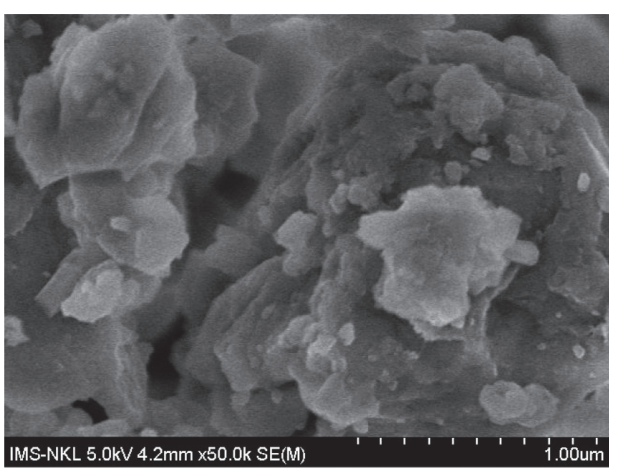

(d)

FIGURE 6: FESEM images of YPS samples at magnification of 5000 times and 50000 times. YPS1 (a, b); YPS2 (c, d).

about 7 times higher than that of the raw sample (no. 2). It is noteworthy that the YPS2 sample also showed good adsorption ability with the Cr (VI) ion removal efficiency of $41.16 \%$ (no. 3) and this sample is chosen to be modified by
$\mathrm{HNO}_{3}, \mathrm{NaOH}$, and EDTA solutions for further Cr (VI) ion adsorption study. However, the modified YPS2 samples using $\mathrm{HNO}_{3}$ solution and EDTA exhibited a decrease in the percentage of removed $\mathrm{Cr}(\mathrm{VI})$ ions (no. 6 and no. 8) while 


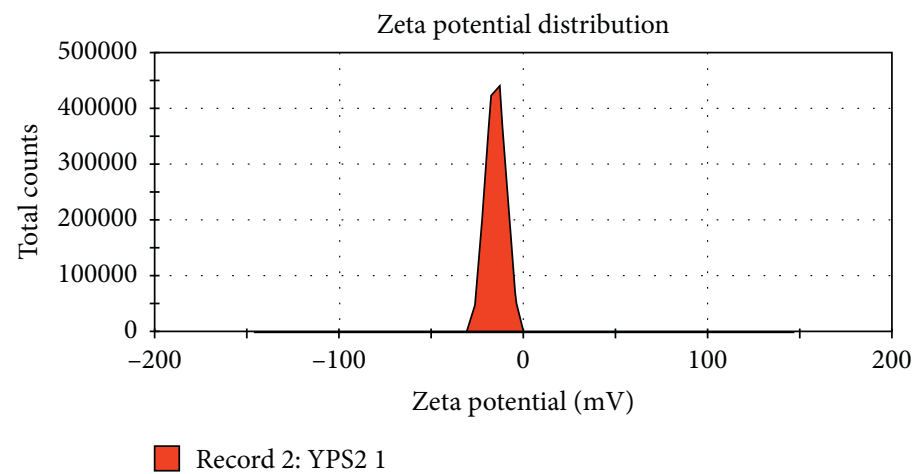

FIgURE 7: Zeta potential distribution diagram of the YPS2 sample.

the modified YPS2 sample using $\mathrm{NaOH}$ solution showed a slight improvement (no. 7). The reduction of Cr (VI) ion adsorption ability by retreated YPS may be due to surface erosion/corrosion of the YPS particles in acid and base environment. The presence of EDTA can lead to the covering of the surface of YPS particles and limit the $\mathrm{Cr}$ (VI) ion adsorption. Therefore, in this study, the YPS2 sample without any further modification will be used for the following experiments.

3.2.2. Assessment on Chromium (VI) Ion Adsorption Ability of Yellow Phosphorus Slag Samples

(1) Effect of Some Experiment Conditions on Chromium (VI) Ion Adsorption Process. The effect of different factors in experimental process such as $\mathrm{pH}$, temperature, YPS2 adsorbent weight, adsorption time, and initial Cr (VI) ion concentration on $\mathrm{Cr}$ (VI) ion adsorption process is investigated. The obtained results are listed in Tables $4-8$.

(i) Effect of $\mathrm{pH}$

Table 4 shows the changes in $\mathrm{Cr}$ (VI) ion removal efficiency of YPS2 samples when the solution $\mathrm{pH}$ is altered from 2 to 7 while the other conditions were fixed $(0.5 \mathrm{~g}$ of adsorbent and 120 minutes of adsorption time). The $\mathrm{Cr}$ (VI) ion adsorption capacity of YPS2 is low for $\mathrm{pH}$ less than or equal 6 with the removal efficiency smaller than $10 \%$. Among investigated solutions, the solution having $\mathrm{pH} 7$ is most suitable for the highest percentage of $\mathrm{Cr}$ (VI) ions adsorbed by the YPS2 sample and the $H$ value of $20.33 \%$, and the amount of $\mathrm{Cr}(\mathrm{VI})$ ions adsorbed per gram of the YPS2 sample is $0.407 \mathrm{mg}$. The $\mathrm{pH}$ higher than 7 was not studied due to the unstableness of $\mathrm{Cr}$ (VI) ions in the alkaline environment [14].

(ii) Effect of adsorbent weight

Table 5 indicates the effect of adsorbent weight on the $\mathrm{Cr}(\mathrm{VI})$ ion adsorption process using YPS2 samples. The mass of adsorbent was changed from $0.1 \mathrm{~g}$ to $1.0 \mathrm{~g}$, the $\mathrm{pH}$ of solution was 7 . and the adsorption time was 120 minutes. It can be seen that adsorbent mass of $1.0 \mathrm{~g}$ presented the lowest $\mathrm{Cr}$ (VI)
TABle 3: Cr (VI) ion adsorption ability of YPS samples.

\begin{tabular}{|c|c|c|c|c|c|}
\hline No. & Sample & $\begin{array}{l}\text { Weight of } \\
\text { adsorbent } \\
\text { (g) }\end{array}$ & $\begin{array}{c}\text { Time of } \\
\text { adsorption } \\
\text { (min) }\end{array}$ & $H(\%)$ & $\begin{array}{c}Q \\
\left(\mathrm{mg} \mathrm{g}^{-1}\right)\end{array}$ \\
\hline 1 & YPS0 & 0.5 & 120 & 4.93 & 0.099 \\
\hline 2 & YPS1 & 0.5 & 120 & 34.43 & 0.689 \\
\hline 3 & YPS2 & 0.5 & 120 & 41.16 & 0.823 \\
\hline 4 & YPSO- $\mathrm{HNO}_{3}$ & 0.5 & 120 & 10.13 & 0.203 \\
\hline 5 & YPS0-NaOH & 0.5 & 120 & 4.27 & 0.085 \\
\hline 6 & YPS2- $\mathrm{HNO}_{3}$ & 0.5 & 120 & 19.68 & 0.394 \\
\hline 7 & YPS2-NaOH & 0.5 & 120 & 41.81 & 0.836 \\
\hline 8 & YPS2-EDTA & 0.5 & 120 & 23.58 & 0.472 \\
\hline
\end{tabular}

TABLE 4: Effect of $\mathrm{pH}$ on $\mathrm{Cr}(\mathrm{VI})$ ion adsorption process.

\begin{tabular}{lcccccc}
\hline No. & Mass $(\mathrm{g})$ & Time $(\mathrm{min})$ & $\mathrm{pH}$ & $\mathrm{Temp} .\left({ }^{\circ} \mathrm{C}\right)$ & $\mathrm{Q}\left({\left.\mathrm{mg} \cdot \mathrm{g}^{-1}\right)}^{\mathrm{H}}(\%)\right.$ \\
\hline 1 & 0.5 & 120 & 2 & 26 & 0.112 & 5.58 \\
2 & 0.5 & 120 & 3 & 26 & 0.090 & 4.49 \\
3 & 0.5 & 120 & 4 & 26 & 0.185 & 9.26 \\
4 & 0.5 & 120 & 5 & 26 & 0.029 & 1.45 \\
5 & 0.5 & 120 & 6 & 26 & 0.090 & 4.49 \\
6 & 0.5 & 120 & 7 & 26 & 0.407 & 20.33 \\
\hline
\end{tabular}

TABLE 5: Effect of adsorbent weight on Cr (VI) ion adsorption process.

\begin{tabular}{lcccccc}
\hline No. & Mass $(\mathrm{g})$ & Time $(\mathrm{min})$ & $\mathrm{pH}$ & $\mathrm{Temp} .\left({ }^{\circ} \mathrm{C}\right)$ & $\mathrm{Q}\left({\left.\mathrm{mg} \cdot \mathrm{g}^{-1}\right)} \mathrm{H}(\%)\right.$ \\
\hline 1 & 0.1 & 120 & 7 & 20 & 2.901 & 29.01 \\
2 & 0.2 & 120 & 7 & 20 & 1.158 & 23.15 \\
3 & 0.3 & 120 & 7 & 20 & 0.728 & 21.85 \\
4 & 0.5 & 120 & 7 & 20 & 0.823 & 41.16 \\
5 & 1 & 120 & 7 & 20 & 0.169 & 16.86 \\
\hline
\end{tabular}

ion removal efficiency and the amount of $\mathrm{Cr}$ (VI) ions removed per gram of the YPS2 sample. The others showed good adsorption ability with the percentage of $\mathrm{Cr}(\mathrm{VI})$ ions removed were higher than $20 \%$. The highest $\mathrm{Cr}$ (VI) ion removal efficiency is achieved using $0.5 \mathrm{~g}$ of YPS2 $(H=41.16 \%)$. 
(iii) Effect of temperature

Table 6 presents the change in $\mathrm{Cr}$ (VI) ion adsorption ability when the experimental temperature is changed from room temperature $\left(26^{\circ} \mathrm{C}\right)$ to $40^{\circ} \mathrm{C}$ and $60^{\circ} \mathrm{C}, \mathrm{pH} 7$ solution, adsorbent weight of $0.5 \mathrm{~g}$, and each experiment was carried out in $120 \mathrm{~min}-$ utes. The highest amount of $\mathrm{Cr}$ (VI) ion removal percentage is obtained at room temperature with the $H$ value of $20.33 \%$. The Cr (VI) ion adsorption capacity of YPS2 was decreased significantly with the increasing adsorption temperature.

(iv) Effect of adsorption time

Table 7 displays the effect of adsorption time on the $\mathrm{Cr}$ (VI) ion adsorption process using YPS2 samples. The adsorption time was changed from 30 to 180 minutes with the optimal adsorbent weight, $\mathrm{pH}$, and temperature. From 30 minutes to 120 minutes, the $\mathrm{Cr}$ (VI) ion adsorption efficiency was increased and reached the highest removal percentage of $30.53 \%$ for 120 minutes. This can be explained as the adsorption is the process of heavy metal ions being adsorbed onto the surface of the adsorbent and the longer the reaction time, the more the metal ions being adsorbed. However, after 150 minutes, the $\mathrm{Cr}$ (VI) ion removal efficiency dropped remarkably, this may due to the saturated state on the YPS2 sample surface.

(v) Effect of initial Cr (VI) ion concentration

Table 8 describes the effect of initial Cr (VI) ion concentration (changing from $10 \mathrm{mg} / \mathrm{L}$ to $100 \mathrm{mg} /$ L) on Cr (VI) ion adsorption ability of YPS2. As can be seen in Table 8, the highest Cr (VI) ion removal efficiency occurred with the initial concentration of $10 \mathrm{mg} \mathrm{Cr}$ (VI) per 1L of solution with the amount of removed ions is $0.407 \mathrm{mg}$ per $1 \mathrm{~g}$ of slag and $H=20.33 \%$. When initial $\mathrm{Cr}(\mathrm{VI})$ ion concentration was increased to $50 \mathrm{mg} / \mathrm{L}$, the Cr (VI) ion adsorption capacity was slightly decreased. Then, it was dropped significantly when the initial Cr (VI) ion concentration is $80 \mathrm{mg} / \mathrm{L}$ and $100 \mathrm{mg} / \mathrm{L}$. This shows that the Cr (VI) ion adsorption ability of YPS2 is higher at low initial concentration of $\mathrm{Cr}$ (VI) ion solution.

From all the tables above, we can see that the Cr (VI) ion adsorption capacity of YPS2 samples is not good with the adsorption efficiency less than 50\%, so further study on adsorption isotherms and adsorption kinetics will not be carried out in this paper.

\subsubsection{Assessment on Methylene Blue Adsorption Ability of} Yellow Phosphorus Slag Samples. Similar to Cr (VI) ion adsorption process using YPS2 samples, some experimental conditions such as $\mathrm{pH}$, adsorbent weight, adsorption temperature, time, and initial concentration of methylene blue (MB) solution were investigated to determine the most suitable condition for $\mathrm{MB}$ adsorption process. The results of
TABLE 6: Effect of temperature on the Cr (VI) ion adsorption process.

\begin{tabular}{lcccccc}
\hline No. & Mass $(\mathrm{g})$ & Time $(\mathrm{min})$ & $\mathrm{pH}$ & $\mathrm{Temp} .\left({ }^{\circ} \mathrm{C}\right)$ & $\mathrm{Q}\left(\mathrm{mg} \cdot \mathrm{g}^{-1}\right)$ & $H(\%)$ \\
\hline 1 & 0.5 & 120 & 7 & 26 & 0.407 & 20.33 \\
2 & 0.5 & 120 & 7 & 40 & 0.090 & 4.49 \\
3 & 0.5 & 120 & 7 & 60 & 0.003 & 0.15 \\
\hline
\end{tabular}

TABLE 7: Effect of adsorption time on the Cr (VI) ion adsorption process.

\begin{tabular}{lcccccc}
\hline No. & Mass $(\mathrm{g})$ & Time $(\mathrm{min})$ & $\mathrm{pH}$ & $\mathrm{Temp} .\left({ }^{\circ} \mathrm{C}\right)$ & $\mathrm{Q}\left(\mathrm{mg} \cdot \mathrm{g}^{-1}\right)$ & $H(\%)$ \\
\hline 1 & 0.5 & 30 & 7 & 25 & 0.003 & 0.15 \\
2 & 0.5 & 60 & 7 & 25 & 0.029 & 1.45 \\
3 & 0.5 & 90 & 7 & 25 & 0.129 & 6.44 \\
4 & 0.5 & 120 & 7 & 25 & 0.611 & 30.53 \\
5 & 0.5 & 150 & 7 & 25 & 0.116 & 5.79 \\
6 & 0.5 & 180 & 7 & 25 & 0.394 & 19.68 \\
\hline
\end{tabular}

TABle 8: Effect of initial concentration on the Cr (VI) ion adsorption process.

\begin{tabular}{lccccc}
\hline No. & $\begin{array}{c}\text { Concentration } \\
(\mathrm{mg} / \mathrm{L})\end{array}$ & $\begin{array}{c}\text { Volume } \\
(\mathrm{mL})\end{array}$ & $\mathrm{pH}$ & $\mathrm{Q}\left(\mathrm{mg} \cdot \mathrm{g}^{-1}\right)$ & $H(\%)$ \\
\hline 1 & 10 & 100 & 7 & 0.407 & 20.33 \\
2 & 20 & 100 & 7 & 0.385 & 19.24 \\
3 & 30 & 100 & 7 & 0.381 & 19.03 \\
4 & 50 & 100 & 7 & 0.307 & 15.34 \\
5 & 80 & 100 & 7 & 0.090 & 4.49 \\
6 & 100 & 100 & 7 & 0.003 & 0.15 \\
\hline
\end{tabular}

removal efficiency and amount of $\mathrm{MB}$ removed per gram of YPS2 are listed in Tables 9-13.

(1) Effect of Some Conditions on the Methylene Blue Adsorption Process.

\section{(i) Effect of $\mathrm{pH}$}

Table 9 describes the effect of $\mathrm{pH}$ on the $\mathrm{MB}$ adsorption process using YPS2 samples. It is clear that the MB adsorption ability of YPS2 samples was high for all the tested $\mathrm{pH}$ with the percentages of $\mathrm{MB}$ removed were all more than $90 \%$. Among the examined $\mathrm{pH}$, the highest $\mathrm{MB}$ removal efficiency was observed at $\mathrm{pH} 3(H=98.20 \%)$, followed at $\mathrm{pH} 7$ $(H=97.63 \%)$. However, since the adsorption process was in aqueous solution, the high acidity environment was undesirable, so the $\mathrm{pH}=7$ was chosen for the further experiments.

(ii) Effect of adsorbent weight

Table 10 demonstrates the MB removal efficiency when the adsorbent weight was changed from $0.2 \mathrm{~g}$ to $1.0 \mathrm{~g}$. All tested samples exhibited high percentage of removed MB. While using $0.2 \mathrm{~g}$ of YPS2, the highest amount of removed $\mathrm{MB}$ per gram of YPS2 adsorbent used $(Q)$ was $4.692 \mathrm{mg} / \mathrm{g}$. While using $0.4 \mathrm{~g}$ of YPS2, the highest percentage of removed MB $(H)$ was $97.63 \%$. This can be caused by the different contact of the adsorbent and $\mathrm{MB}$ 
TABLE 9: Effect of pH on methylene blue adsorption process.

\begin{tabular}{lccccc}
\hline No. & Mass $(\mathrm{g})$ & Time $(\mathrm{min})$ & $\mathrm{pH}$ & $\mathrm{Q}\left(\mathrm{mg}^{\mathrm{g}} \mathrm{g}^{-1}\right)$ & $H(\%)$ \\
\hline 2 & 0.4 & 120 & 3 & 2.455 & 98.20 \\
3 & 0.4 & 120 & 4 & 2.434 & 97.35 \\
4 & 0.4 & 120 & 5 & 2.350 & 94.02 \\
5 & 0.4 & 120 & 6 & 2.403 & 96.11 \\
6 & 0.4 & 120 & 7 & 2.441 & \\
\hline
\end{tabular}

TABLE 10: Effect of adsorbent weight on methylene blue adsorption process.

\begin{tabular}{lccccc}
\hline No. & Mass $(\mathrm{g})$ & Time $(\mathrm{min})$ & $\mathrm{pH}$ & $\mathrm{Q}\left({\left.\mathrm{mg} \cdot \mathrm{g}^{-1}\right)}\right.$ & $H(\%)$ \\
\hline 1 & 0.2 & 120 & 7 & 4.692 & 93.85 \\
2 & 0.3 & 120 & 7 & 3.200 & 95.99 \\
3 & 0.4 & 120 & 7 & 2.441 & 97.63 \\
4 & 0.5 & 120 & 7 & 1.924 & 96.22 \\
5 & 1.0 & 120 & 7 & 0.964 & 96.39 \\
\hline
\end{tabular}

TABLE 11: Effect of temperature on methylene blue adsorption process.

\begin{tabular}{lccccc}
\hline No. & Mass $(\mathrm{g})$ & Time $(\mathrm{min})$ & Temp. $\left({ }^{\circ} \mathrm{C}\right)$ & $Q\left({\left.\mathrm{mg} \cdot \mathrm{g}^{-1}\right)}\right.$ & $H(\%)$ \\
\hline 1 & 0.4 & 120 & 30 & 2.441 & 97.63 \\
2 & 0.4 & 120 & 45 & 2.435 & 97.41 \\
3 & 0.4 & 120 & 65 & 2.458 & 98.31 \\
\hline
\end{tabular}

TABLE 12: Effect of adsorption time on methylene blue adsorption process.

\begin{tabular}{lcccccc}
\hline No. & $\begin{array}{c}\text { Mass } \\
(\mathrm{g})\end{array}$ & $\begin{array}{c}\text { Time } \\
(\mathrm{min})\end{array}$ & $\begin{array}{c}\text { Volume } \\
(\mathrm{mL})\end{array}$ & $\mathrm{pH}$ & $\begin{array}{c}\mathrm{Q} \\
\left(\mathrm{mg}^{-1}\right)\end{array}$ & $H(\%)$ \\
\hline 1 & 0.4 & 30 & 100 & 7 & 2.359 & 94.36 \\
2 & 0.4 & 60 & 100 & 7 & 2.374 & 94.98 \\
4 & 0.4 & 120 & 100 & 7 & 2.441 & 97.63 \\
5 & 0.4 & 150 & 100 & 7 & 2.459 & 98.37 \\
6 & 0.4 & 180 & 100 & 7 & 2.401 & 96.05 \\
7 & 0.4 & 30 & 100 & 4 & 2.425 & 97.01 \\
8 & 0.4 & 60 & 100 & 4 & 2.401 & 96.05 \\
9 & 0.4 & 120 & 100 & 4 & 2.455 & 98.20 \\
10 & 0.4 & 150 & 100 & 4 & 2.445 & 97.80 \\
11 & 0.4 & 180 & 100 & 4 & 2.421 & 96.84 \\
\hline
\end{tabular}

TABLE 13: Effect of initial concentration on the methylene blue adsorption process.

\begin{tabular}{lccccc}
\hline No. & $\begin{array}{c}\text { Concentration } \\
(\mathrm{mg} / \mathrm{L})\end{array}$ & $\begin{array}{c}\text { Volume } \\
(\mathrm{mL})\end{array}$ & $\mathrm{pH}$ & $\mathrm{Q}\left(\mathrm{mg}^{\mathrm{g}} \mathrm{g}^{-1}\right)$ & $H(\%)$ \\
\hline 1 & 5 & 100 & 7 & 2.396 & 95.82 \\
2 & 10 & 100 & 7 & 2.441 & 97.63 \\
3 & 15 & 100 & 7 & 2.317 & 92.66 \\
4 & 20 & 100 & 7 & 2.226 & 89.05 \\
5 & 25 & 100 & 7 & 2.184 & 87.35 \\
\hline
\end{tabular}

molecules in solution at various amounts of the adsorbent. Therefore, the YPS2 adsorbent weight of $0.4 \mathrm{~g}$ was selected for further investigation.

(iii) Effect of temperature

Table 11 presents the effect of adsorption temperature on the MB adsorption process using YPS2 samples. The temperature was changed from $30^{\circ} \mathrm{C}$ to $65^{\circ} \mathrm{C}$. The $\mathrm{MB}$ removal efficiency using YPS2 samples was the highest at $65^{\circ} \mathrm{C}$ with $H=98.31 \%$ and lowest at $45^{\circ} \mathrm{C}$ with $H=97.41 \%$. The amount of MB removed per gram of YPS2 samples $(Q)$ under different temperatures also followed that order.

(iv) Effect of adsorption time

Table 12 performs how changing the adsorption time can influence the MB adsorption capacity of YPS2 samples. The time was altered from $30 \mathrm{~min}$ utes to 180 minutes, and the experiments were carried out in two different $\mathrm{pH}$ solutions ( $\mathrm{pH} 4$ and $\mathrm{pH}$ 7). For $\mathrm{pH} 7$ solution, the MB removal efficiency was increased with rising adsorption time and reached the highest percentage of MB removed of 98.37\% after 150 minutes. After that, the MB adsorption capacity of the YPS2 sample was decreased. This might also be due to the saturation on the surface of YPS2 samples. The same pattern was observed with the $\mathrm{pH} 4$ solution and the highest $\mathrm{MB}$ removal efficiency of $98.20 \%$ after 120 minutes of adsorption time. It can be seen from this table that there is a slight difference in the percentage of $\mathrm{MB}$ removed by the YPS2 sample in $\mathrm{pH} 4$ and $\mathrm{pH} 7$; however, after 120 minutes of testing, the YPS2 sample exhibited a good MB adsorption ability. Therefore, the suitable time for the MB adsorption study by the YPS2 sample is 120 minutes.

(v) Effect of initial MB concentration

Table 13 displays the changes in the percentage of removed MB by using YPS2 samples when the initial $\mathrm{MB}$ concentration was altered from $5 \mathrm{mg} / \mathrm{L}$ to $25 \mathrm{mg} / \mathrm{L}$. The highest MB removal efficiency was obtained when the initial $\mathrm{MB}$ concentration was $10 \mathrm{mg} / \mathrm{L}(H=97.63 \%)$. When the initial MB concentration was increased, the MB adsorption capacity of YPS2 was decreased.

Figure 8 shows IR spectra of the YPS2 sample before and after absorbing MB. The presence of MB in YPS2 was reflected by the increase of intensity and the shift of peak at around $1450 \mathrm{~cm}^{-1}\left(1456 \mathrm{~cm}^{-1}\right.$ for the YPS2 sample and $1443 \mathrm{~cm}^{-1}$ for the YPS2-absorbed MB sample). This is due to the consonance of bending vibration of the $\mathrm{CH}_{3}$ group and aromatic $\mathrm{C}=\mathrm{C}$ of $\mathrm{MB}$ with the stretching vibration of the $\mathrm{CO}_{3}^{2-}$ group in calcite in YPS2. Moreover, the stretching vibrations of $\mathrm{C}=\mathrm{N}$ and benzene zing were found at $1594 \mathrm{~cm}^{-1}$ and $1660 \mathrm{~cm}^{-1}$, respectively. These evidences proved that $\mathrm{MB}$ was absorbed onto the YPS2 sample. A hypothesis model for the adsorption of MB by YPS2 particles is shown in Figure 9 [37].

3.2.4. Methylene Blue Adsorption Isotherms. Figure 10 and Table 14 show the parameters of MB adsorption process using YPS according to four isotherm models: Langmuir, Freundlich, Temkin, and Dubinin-Radushkevich. It is clear that the adsorption isotherm of $\mathrm{MB}$ adsorption process using YPS follows the Langmuir model with the highest correlation coefficient $R^{2}=0.96$ which indicated that the 


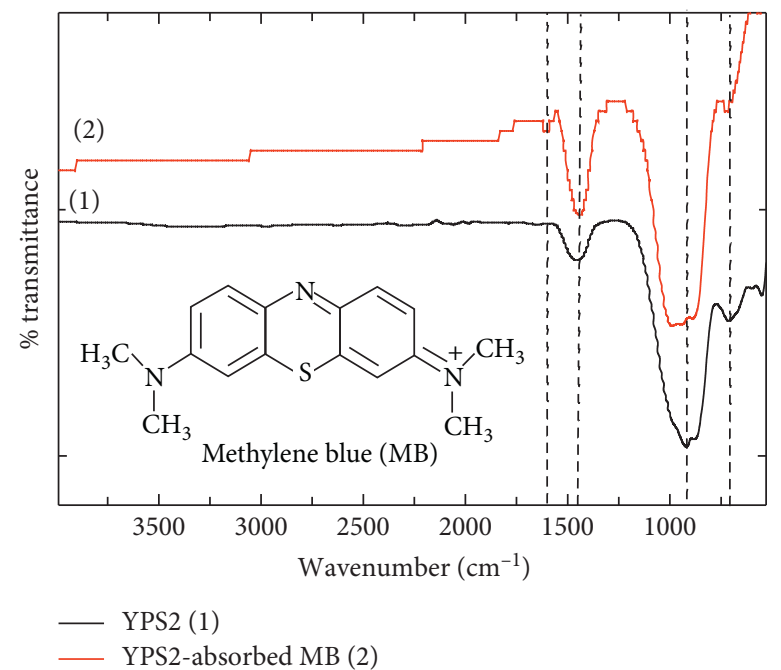

FIGURE 8: IR spectra of the YPS2 sample and YPS2-absorbed methylene blue at initial MB concentration of $10 \mathrm{ppm}$.

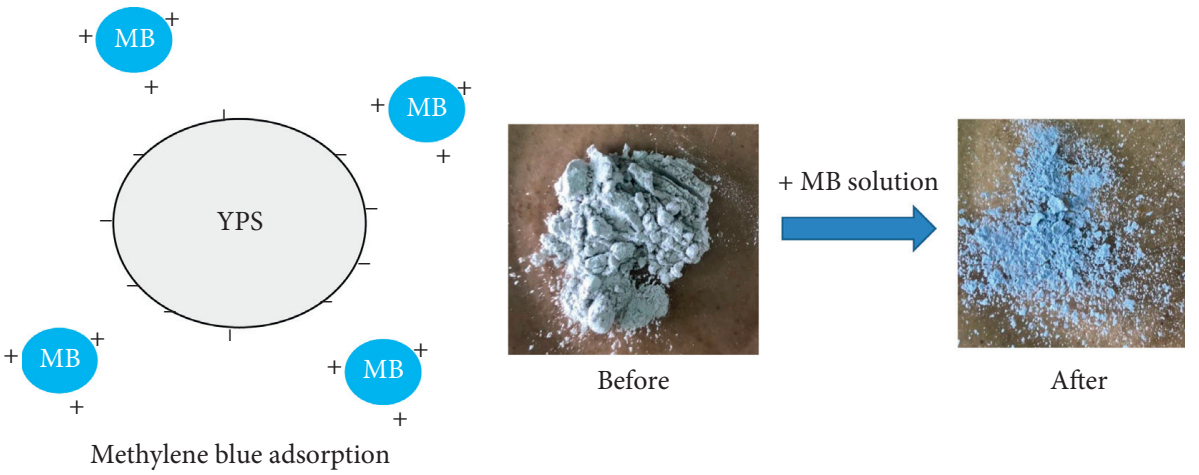

FIGURE 9: A hypothesis model for the adsorption of MB ions by YPS2 particles.

adsorption process is in the monolayer. The separation factor $R_{\mathrm{L}}=0.434$, smaller than 1 , also expressed that the equilibrium adsorption to be in favor. The Freundlich model also demonstrated a relatively high correlation coefficient $R^{2}=0.925$, with the adsorption intensity $n=1.422$ to display the favorable sorption process. The other isotherm models did not fit well with the MB adsorption process using YPS.

Table 15 lists the Langmuir, Freundlich, Temkin, and Dubinin-Radushkevich isotherm constants of $\mathrm{MB}$ adsorption using YPS. It can be recognized that the maximum adsorption capacity $\left(Q_{0}\right)$ of YPS for the removal of MB is $22.989 \mathrm{mg} \cdot \mathrm{g}^{-1}$. As comparison with the $Q_{0}$ of other adsorbents, for example, orange peel, banana peel, natural clay, and fly ash in Table 16, the $Q_{0}$ value of YPS is quite good. This confirms that YPS is a potential absorbent for the removal of $\mathrm{MB}$ in aqueous solution.

3.2.5. Methylene Blue Adsorption Kinetics. MB adsorption kinetics were studied using four linear adsorption kinetic models as represented in Figure 11.

From Figure 11, we can see that all four linear reaction models show good fitting to the adsorption process of $\mathrm{MB}$ using YPS with the correlation coefficient $R^{2}$ all greater than 0.98 . However, the best fit model is the pseudo-second-order reaction model with $R^{2}$ equal to 0.9999 . This is in agreement with publications of $\mathrm{MB}$ adsorption using activated carbon from tea seed shells or Ficus carica bast, using seaweed or modified pumice stone $[28,29,32,33]$.

3.2.6. Methylene Blue Adsorption Thermodynamics. Thermodynamics of MB adsorption process of YPS2 can be calculated according to equations (2)-(4) as reported by Kunde et al. [37] or equations (2) and (3) as reported by Yuh-Shan [40] as follows:

$$
\begin{gathered}
\Delta G^{\mathrm{o}}=-\mathrm{RT} \ln \left(K_{\mathrm{a}}\right), \\
\Delta G^{\mathrm{o}}=\Delta H^{\mathrm{o}}-T \Delta S^{\mathrm{o}},
\end{gathered}
$$

where $R$ is the universal gas constant, $T$ is absolute temperature, $\Delta G^{\circ}$ is Gibbs free energy change, $\Delta H^{\circ}$ is enthalpy change, $\Delta S^{o}$ is entropy change, and $K_{\mathrm{a}}$ is the Langmuir constant which was calculated as suggested in References $[40,41]$.

Herein, isotherm data were analyzed at 303, 313, and $323 \mathrm{~K}$. From $K_{\mathrm{a}}$ values obtained from Langmuir isotherms at different temperatures, three $\Delta G^{\circ}$ values were calculated and are presented in Table 17. It can be seen that the $\Delta G^{\circ}$ values 


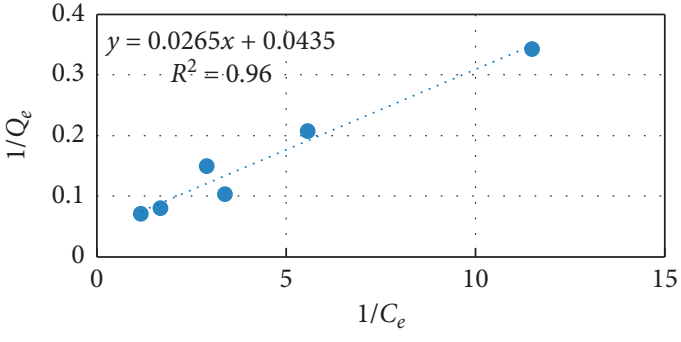

(a)

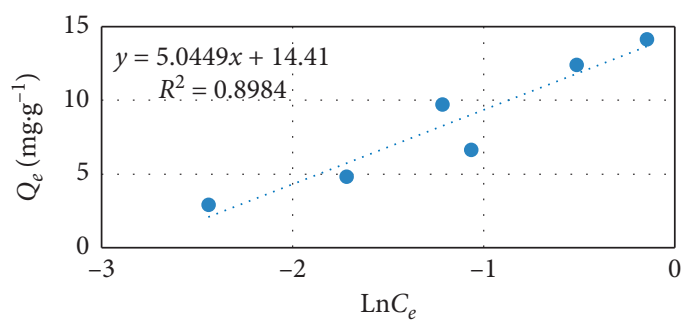

(c)

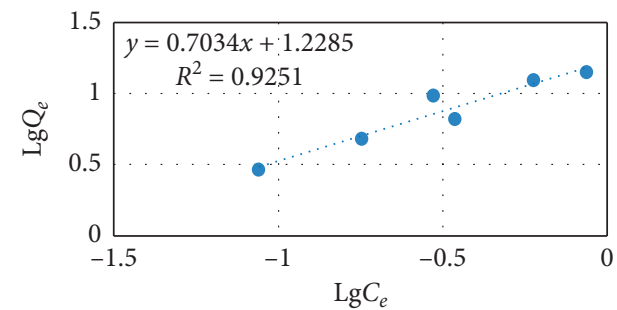

(b)

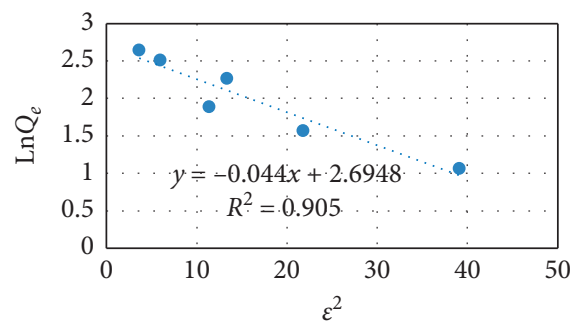

(d)

FIGURE 10: Four isotherm models with equations and correlation coefficient values of MB adsorption using YPS. (a) Langmuir adsorption isotherm. (b) Freundlich adsorption isotherm. (c) Temkin adsorption isotherm. (d) Dubinin-Radushkevich adsorption isotherm.

TABle 14: Parameters for plotting adsorption isotherms of MB adsorption using YPS.

\begin{tabular}{lcccccccccc}
\hline No. & $C_{\mathrm{o}}\left(\mathrm{mg} \cdot \mathrm{L}^{-1}\right)$ & $C_{\mathrm{e}}\left(\mathrm{mg} \cdot \mathrm{L}^{-1}\right)$ & $1 / C_{\mathrm{e}}$ & $\log C_{\mathrm{e}}$ & $\operatorname{Ln} C_{\mathrm{e}}$ & $Q_{\mathrm{e}}\left(\mathrm{mg} \cdot \mathrm{g}^{-1}\right)$ & $1 / Q_{\mathrm{e}}$ & $\log Q_{\mathrm{e}}$ & $\operatorname{Ln} Q_{\mathrm{e}}$ & $\varepsilon^{2}$ \\
\hline 1 & 3 & 0.09 & 11.49 & -1.06 & -2.44 & 2.91 & 0.34 & 0.46 & 1.07 & 39.14 \\
2 & 5 & 0.18 & 5.57 & -0.75 & -1.72 & 4.82 & 0.21 & 0.68 & 1.57 & 21.77 \\
3 & 7 & 0.34 & 2.90 & -0.46 & -1.07 & 6.66 & 0.15 & 0.82 & 1.90 & 11.38 \\
4 & 10 & 0.30 & 3.38 & -0.53 & -1.22 & 9.70 & 0.10 & 0.99 & 2.27 & 13.38 \\
5 & 13 & 0.60 & 1.67 & -0.22 & -0.52 & 12.40 & 0.08 & 1.09 & 2.52 & 5.94 \\
6 & 15 & 0.86 & 1.16 & -0.06 & -0.15 & 14.14 & 0.07 & 1.15 & 2.65 & 3.62 \\
\hline
\end{tabular}

$C_{\mathrm{o}}$ and $C_{\mathrm{e}}$ : initial $\mathrm{MB}$ concentration and absorbed $\mathrm{MB}$ concentration, respectively.

TAвLE 15: Langmuir, Freundlich, Temkin, and Dubinin-Radushkevich isotherm constants of MB adsorption using YPS.

\begin{tabular}{|c|c|c|c|c|c|c|c|}
\hline \multicolumn{4}{|c|}{ Langmuir constant } & \multicolumn{4}{|c|}{ Freundlich constant } \\
\hline$Q_{\mathrm{o}}\left(\mathrm{mg} \cdot \mathrm{g}^{-1}\right)$ & $K_{\mathrm{L}}\left(\mathrm{L} \cdot \mathrm{mg}^{-1}\right)$ & $R_{\mathrm{L}}$ & $R^{2}$ & $1 / n$ & $\mathrm{~N}$ & $k_{\mathrm{f}}\left(\mathrm{mg} \cdot \mathrm{g}^{-1}\right)$ & $R^{2}$ \\
\hline 22.989 & 1.642 & 0.434 & 0.960 & 0.703 & 1.422 & 16.924 & 0.925 \\
\hline \multicolumn{4}{|c|}{ Temkin constant } & \multicolumn{4}{|c|}{ Dubinin-Radushkevich constant } \\
\hline$A_{\mathrm{T}}\left(\mathrm{L} \cdot \mathrm{mg}^{-1}\right)$ & $b_{\mathrm{T}}$ & $B\left(\mathrm{~J} \cdot \mathrm{mol}^{-1}\right)$ & $R^{2}$ & $Q_{\mathrm{s}}\left(\mathrm{mg} \cdot \mathrm{g}^{-1}\right)$ & $K_{\mathrm{ad}}\left(\mathrm{mol}^{2} \cdot \mathrm{kJ}^{-2}\right)$ & $E\left(\mathrm{~kJ} \cdot \mathrm{mol}^{-1}\right)$ & $R^{2}$ \\
\hline 17.398 & 491.104 & 5.045 & 0.898 & 14.803 & 0.044 & 3.370 & 0.905 \\
\hline
\end{tabular}

TABLE 16: Comparison of adsorption capacity of several low-cost adsorbents for the uptake of methylene blue from aqueous solutions.

\begin{tabular}{lcc}
\hline Adsorbents & Sorption capacity $Q_{\mathrm{o}}\left(\mathrm{mg}^{-1} \mathrm{~g}^{-1}\right)$ & References \\
\hline Activated date pits & 12.90 & {$[38]$} \\
Fly ash & 5.57 & {$[38]$} \\
Orange peel & 18.60 & {$[38]$} \\
Glass & 2.24 & {$[38]$} \\
Clay & 6.30 & {$[38]$} \\
Natural clay & 15.40 & {$[38]$} \\
Silica nanosheets & 11.77 & {$[38]$} \\
Ilmenite nanoparticles & 71.90 & {$[38]$} \\
Banana peel & 20.80 & {$[38]$} \\
Garlic peel & 142.86 & {$[39]$} \\
Mango seed kernel & 142.86 & {$[39]$} \\
Rejected tea & 156.00 & {$[39]$} \\
Neem leaves & 8.76 & {$[39]$} \\
Empty fruit bunch & 50.76 & This work \\
YPS & 22.99 & \\
\end{tabular}




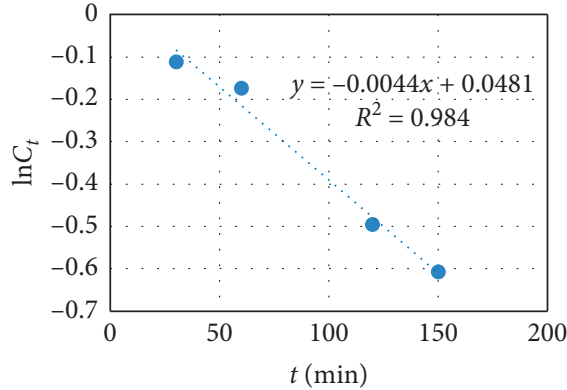

(a)

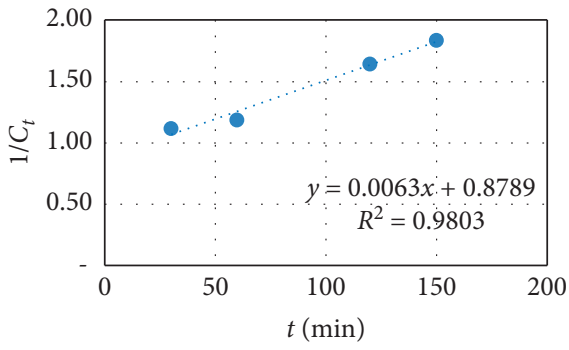

(c)

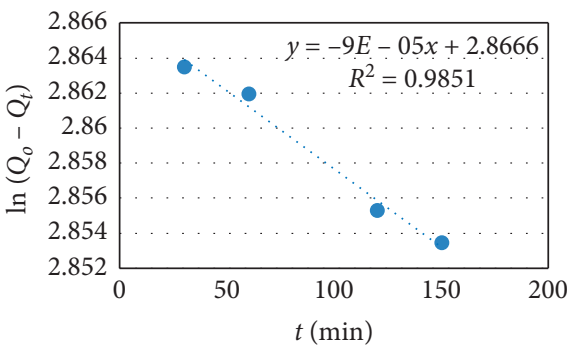

(b)

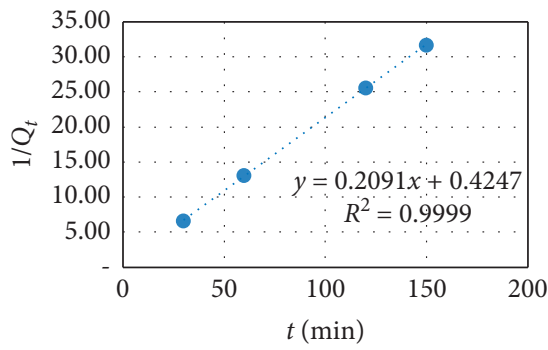

(d)

FIGURE 11: Adsorption kinetics of MB adsorption process using YPS. (a) First-order reaction model. (b) Pseudo-first-order reaction model. (c) Second-order reaction model. (d) Pseudo-second-order reaction model.

TABLE 17: Thermodynamic parameters of MB adsorption process by the YPS2 sample.

\begin{tabular}{lcccc}
\hline \multirow{2}{*}{ Adsorbent } & \multicolumn{3}{c}{ Thermodynamic parameters } \\
& $T(\mathrm{~K})$ & $\Delta G^{\mathrm{o}}\left(\mathrm{kJ} \cdot \mathrm{mol}^{-1}\right)$ & $\Delta H^{\mathrm{o}}\left(\mathrm{kJ} \cdot \mathrm{mol}^{-1}\right)$ & $\Delta S^{\mathrm{o}}\left(\mathrm{kJ} \cdot \mathrm{mol}^{-1} \cdot \mathrm{K}^{-1}\right)$ \\
\hline \multirow{3}{*}{ Methylene blue } & 303 & -32.6642 & & -74.017 \\
& 313 & -30.7693 & -0.1371 \\
\hline
\end{tabular}

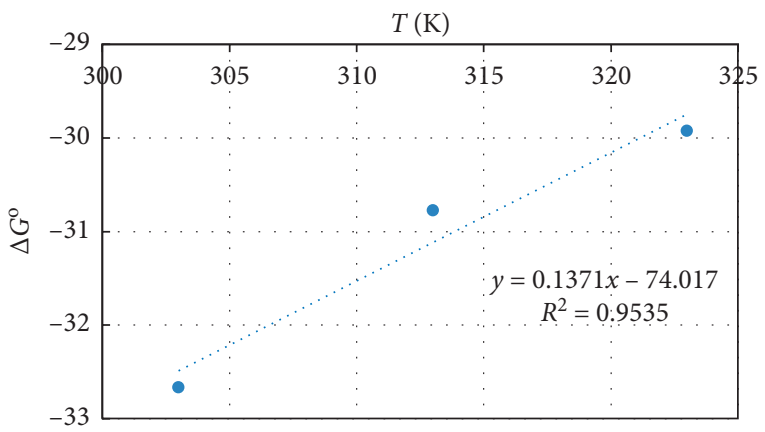

Figure 12: Plot of Gibbs free energy change, $\Delta G^{\mathrm{o}}$, versus temperature $(T)$.

are negative; it means that $\mathrm{MB}$ adsorption processes occur spontaneously. The $\Delta G^{\circ}$ increased with rising temperature indicates more energetically favorable adsorption [37]. From the plot of the $\Delta G^{\mathrm{o}}$ values versus $T$ in Figure $12\left(R^{2}=0.9535\right), \Delta H^{\mathrm{o}}$ and $\Delta S^{\mathrm{o}}$ were also calculated and are listed in Table 17. The negative $\Delta H^{\circ}$ indicating that the sorption reaction is exothermic and the negative $\Delta S^{\circ}$ value showed a decrease in the randomness at the solid/solution interface during the sorption process of MB onto YPS2.

\section{Conclusion}

In conclusion, the yellow phosphorus slag (YPS) after being washed with water and wet milled (YPS2) showed a finer particle size and a good adsorption ability of chromium (VI) and methylene blue (MB). The surface of YPS2 has a negative charge. The main composition of YPS2 is calcite, and main oxides of YPS2 are $\mathrm{SiO}_{2}$ and $\mathrm{CaO}$. The most suitable condition for the chromium (VI) adsorption process was as follows: solution $\mathrm{pH}$ of 7 , adsorption time of 120 minutes, 
and the chromium (VI) initial concentration of $10 \mathrm{mg} / \mathrm{L}$. The neutral $\mathrm{pH}$ environment will not create secondary pollution. For chromium (VI) ion adsorption, YPS was not a suitable adsorbent due to low adsorption efficiency, less than 50\%. In the case of $\mathrm{MB}$, treated YPS was a promising adsorption material with high $\mathrm{MB}$ removal percentage, over $85 \%$. The FTIR spectrum of YPS2-absorbed MB confirmed that MB was absorbed onto YPS2. The adsorption isotherm of MB adsorption process using YPS2 follows the Langmuir isotherm with $R^{2}=0.96$, and the adsorption kinetic fits well with the pseudo-second-order reaction model with $R^{2}=0.999$. The obtained thermodynamic parameters confirmed that the MB adsorption process onto YPS2 is favorable spontaneous adsorption. These results were also in agreement with others research studies on $\mathrm{MB}$ adsorption process using various adsorbents.

\section{Data Availability}

The data used to support the findings of this study are included within the article.

\section{Conflicts of Interest}

The authors declare that there are no conflicts of interest.

\section{Acknowledgments}

The authors would like to thank the Vietnam Academy of Science and Technology for financial support (subject code UDNGDP.04/19-20, period 2019-2020).

\section{References}

[1] Y. Su, G. B. Li, and J. P. Xia, "Kinetic study of Fe removal from precipitated silica prepared from yellow phosphorus slag," The Canadian Journal of Chemical Engineering, vol. 87, no. 4, pp. 610-613, 2009.

[2] http://www.potashcorp.com/overview/nutrients/phosphate/ overview/industrial-andfood-phosphate-uses-and-regions.

[3] D. You, "Preparation and properties of alkali-activated cement containing phosphorous slag and fly ash," CeramicsSilikaty, vol. 60, pp. 63-67, 2016.

[4] L. Hong-pan, H. Xiao-feng, M. Li-ping, C. Dan-li, S. Zhi-biao, and J. Ming, "Effect of $\mathrm{Fe}_{2} \mathrm{O}_{3}$ on the crystallization behavior of glass-ceramics produced from naturally cooled yellow phosphorus furnace slag," International Journal of Minerals, Metallurgy, and Materials, vol. 24, pp. 316-323, 2017.

[5] Z. Karshigina, Z. Abisheva, Y. Bochevskaya, A. Akcil, and E. Sargelova, "Recovery of rare earth metals and precipitated silicon dioxide from phosphorus slag," Minerals Engineering, vol. 77, pp. 159-166, 2015.

[6] http://congnghiepmoitruong.vn/giai-phap-su-dung-xi-thaitu-hoat-dong-san-xuat-phot-pho-vang/.

[7] Q. Guoping, W. Kun, B. Xianping, X. Ting, J. Dazhong, and H. Qianjin, "Effects of surface modified phosphate slag powder on performance of asphalt and asphalt mixture," Construction and Building Materials, vol. 158, 2017.

[8] S. Yanping, Z. Ben, Y. Yu, C. Huaxin, X. Rui, and G. Jiuguang, "Effects of phosphorus slag powder and polyester fiber on performance characteristics of asphalt binders and resultant mixtures," Construction and Building Materials, vol. 141, pp. 289-295, 2017.

[9] C. Jia-sheng, Z. Bin, W. Xin-min, Z. Qin-li, and W. Li, "Cemented backfilling performance of yellow phosphorus slag," International Journal of Minerals Metallurgy and Materials, vol. 17, pp. 121-126, 2010.

[10] Z. Zengqi, Q. Wang, and Y. Jun, "Hydration mechanisms of composite binders containing phosphorus slag at different temperatures," Construction and Building Materials, vol. 147, pp. 720-732, 2017.

[11] German Auslegeschrift No. 1,804,172.

[12] German Auslegeschrift No. 2,211,505.

[13] W. Kerstan, "Method of refining the silicatic slag phase obtained in the thermal recovery of phosphorus from phosphates," US Patent No. 4,243,425, 1981.

[14] S. Aber, A. R. Amani-Ghadim, and V. Mirzajani, "Removal of $\mathrm{Cr}(\mathrm{VI})$ from polluted solutions by electrocoagulation: modeling of experimental results using artificial neural network," Journal of Hazardous Materials, vol. 171, no. 1-3, pp. 484-490, 2009.

[15] N. Goyal, S. C. Jain, and U. C. Banerjee, "Comparative studies on the microbial adsorption of heavy metals," Advances in Environmental Research, vol. 7, no. 2, pp. 311-319, 2003.

[16] D. C. Sharma and C. F. Forster, "Column studies into the adsorption of chromium (VI) using sphagnum moss peat," Bioresource Technology, vol. 52, no. 3, pp. 261-267, 1995.

[17] S. Arivoli, M. Hema, M. Karuppaiah, and S. Saravanan, "Adsorption of chromium ion by acid activated low cost carbon-kinetic, mechanistic, thermodynamic and equilibrium studies," E-Journal of Chemistry, vol. 5, no. 4, pp. 820-831, 2008.

[18] K. Mohanty, M. Jha, B. C. Meikap, and M. N. Biswas, "Removal of chromium (VI) from dilute aqueous solutions by activated carbon developed from Terminalia arjuna nuts activated with zinc chloride," Chemical Engineering Science, vol. 60, no. 11, pp. 3049-3059, 2005.

[19] K. C. T. De Brito, R. Cecchini, J. A. V. Rocha, and M. F. V. Vargas, "Mutagenicity of sediments and biomarkers of oxidative stress in fish from aquatic environments under the influence of tanneries," Mutation Research, vol. 561, no. 1-20, pp. 101-117, 2004.

[20] A. Ali, K. Saeed, and F. Mabood, "Removal of chromium (VI) from aqueous medium using chemically modified banana peels as efficient low-cost adsorbent," Alexandria Engineering Journal, vol. 55, no. 3, pp. 2933-2942, 2016.

[21] K. Mulani, S. Daniels, K. Rajdeo, S. Tambe, and N. Chavan, "Adsorption of chromium (VI) from aqueous solutions by coffee polyphenol-formaldehyde/acetaldehyde resins," Journal of Polymers, vol. 2013, pp. 1-11, 2013.

[22] N. T. Chinh, H. Thai, T. D. M. Tran et al., "Adsorption of mercuric ion from aqueous solutions using modified fly ash," Vietnam Journal of Science and Technology, vol. 56, no. 6, pp. 688-697, 2018.

[23] S. O. Owalude and A. C. Tella, "Removal of hexavalent chromium from aqueous solutions by adsorption on modified groundnut hull," Beni-Suef University Journal of Basic and Applied Sciences, vol. 5, no. 4, pp. 377-388, 2016.

[24] P. Pandey, S. Sharma, and S. Sambi, "Kinetics and equilibrium study of chromium adsorption on zeolite $\mathrm{NaX}$," International Journal of Environmental Science and Technology, vol. 7, no. 2, pp. 395-404, 2010.

[25] O. Gulnaz, A. Kaya, F. Matyar, and B. Arikan, "Sorption of basic dyes from aqueous solution by activated sludge," Journal of Hazardous Materials, vol. 108, no. 3, pp. 183-188, 2004. 
[26] W. T. Tsai, C. Y. Chang, M. C. Lin, S. F. Chien, H. F. Sun, and M. F. Hsieh, "Adsorption of acid dye onto activated carbons prepared from agricultural waste bagasse by $\mathrm{ZnCl}_{2}$ activation," Chemosphere, vol. 45, no. 1, pp. 51-58, 2001.

[27] B. E. Barragán, C. Costa, and M. Carmen Márquez, "Biodegradation of azo dyes by bacteria inoculated on solid media," Dyes and Pigments, vol. 75, no. 1, pp. 73-81, 2007.

[28] Z. Aksu, "Application of biosorption for the removal of organic pollutants: a review," Process Biochemistry, vol. 40, no. 3-4, pp. 997-1026, 2005.

[29] D. Pathania, S. Sharma, and P. Singh, "Removal of methylene blue by adsorption onto activated carbon developed from Ficus carica bast," Arabian Journal of Chemistry, vol. 10, pp. S1445-S1451, 2017.

[30] M. Khodaie, N. Ghasemi, B. Moradi, and M. Rahimi, "Removal of methylene blue from wastewater by adsorption onto $\mathrm{ZnCl}_{2}$ activated corn husk carbon equilibrium studies," Journal of Chemistry, vol. 2013, pp. 1-6, 2013.

[31] M. Fatiha and B. Benguella, "Adsorption of methylene blue from aqueous solutions using natural clay," Journal of Materials and Environmental Science, vol. 7, pp. 285-292, 2016.

[32] R. R. Elmorsi, S. T. El-Wakeel, W. A. Shehab El-Dein et al., "Adsorption of methylene blue and $\mathrm{Pb}^{2+}$ by using acid-activated Posidonia oceanica waste," Scientific Reports, vol. 9, no. 1, 2019.

[33] Z. Derakhshan, M. A. Baghapour, M. Ranjbar, and M. Faramarzian, "Adsorption of methylene blue dye from aqueous solutions by modified pumice stone: kinetics and equilibrium studies," Health Scope, vol. 2, no. 3, pp. 136-144, 2013.

[34] A. Zinesh, Z. Karshigina, Y. Bochevskaya et al., "Recovery of rare earth metals as critical raw materials from phosphorus slag of long-term storage," Hydrometallurgy, vol. 173, pp. 271-282, 2017.

[35] J. Ming, Z. Jian-Yu, W. Xiao-Rong et al., "Migration and transformation behavior of harmful elements of lightweight ceramsite preparation from yellow phosphorus slag," IOP Conference Series: Earth and Environmental Science, vol. 199, Article ID 042033, 2018.

[36] X. Huang, L. Liu, X. Zhao, C. Tang, and X. Wang, "Properties of phosphorus-slag-based cementitious pastes for stabilizing lead," Materials, vol. 12, no. 23, p. 3831, 2019.

[37] G. B. Kunde, B. Sehgal, and A. K. Ganguli, "Synthesis of mesoporous rebar MWCNT/alumina composite (RMAC) nodules for the effective removal of methylene blue and $\mathrm{Cr}$ (VI) from an aqueous medium," Journal of Hazardous Materials, vol. 374, pp. 140-151, 2019.

[38] S. U. Subhransu, B. Sushmita, and C. S. Yogesh, "Application of natural clay as a potential adsorbent for the removal of a toxic dye from aqueous solutions," Desalination and Water Treatment, vol. 52, no. 34-36, pp. 6703-6711, 2014.

[39] Z. R. Nur, A. W. Wan, G. Karim, K. M. Dalia, A. R. Nur, and A. M. S. Mohamad, "Adsorption capacity of raw empty fruit bunch biomass onto methylene blue dye in aqueous solution," Journal of Purity, Utility Reaction and Environment, vol. 1, pp. 45-60, 2012.

[40] H. Yuh-Shan, "Isotherms for the sorption of lead onto peat: comparison of linear and non-linear methods," Polish Journal of Environmental Studies, vol. 15, no. 1, pp. 81-86, 2006.

[41] H. Yuh-Shan, C. Wen-Ta, and W. Chung-Chi, "Regression analysis for the sorption isotherms of basic dyes on sugarcane dust," Bioresource Technology, vol. 96, pp. 1285-1291, 2005. 